\title{
How Avatar Customization Affects Fear in a Game-based Digital Exposure Task for Social Anxiety
}

\author{
MARTIN JOHANNES DECHANT, University of Saskatchewan, Canada \\ MAX VALENTIN BIRK, Technical University of Technology Eindhoven, Netherlands \\ YOUSSEF SHIBAN Private University of Applied Sciences Goettingen, Germany \\ KNUT SCHNELL, Dep. of Psychiatry and Psychotherapy, University Medicine Goettingen, Germany \\ REGAN LEE MANDRYK, University of Saskatchewan, Canada
}

\begin{abstract}
The treatment of social anxiety through digital exposure therapy is challenging due to the cognitive properties of social anxiety-individuals need to be fully engaged in the task and feel themselves represented in the social situation; however, avatar customization has been shown to increase both engagement and social presence. In this paper, we harness techniques used in commercial games, and investigate how customizing self-representation in a novel digital exposure task for social anxiety influences the experience of social threat. In an online experiment with 200 participants, participants either customized their avatar or were assigned a predefined avatar. Participants then controlled the avatar through a virtual shop, where they had to solve a math problem, while a simulated audience within the virtual world observed them and negatively judged their performance. Our findings show that we can stimulate the fear of evaluation by others in our task, that fear is driven primarily by trait social anxiety, and that this relationship is strengthened for people higher in trait social anxiety. We provide new insights into the effects of customization in a novel therapeutic context, and embed the discussion of avatar customization into related work in social anxiety and humancomputer interaction.
\end{abstract}

CCS Concepts: •Human-centered computing Human computer interaction (HCI) -Empirical studies in HCI -Applied computing Life and medical sciences Consumer health •Applied computing Computers in other domains $\sim$ Personal computers and $\mathrm{PC}$ applications $\sim$ Computer games

KEYWORDS: Social Anxiety, Gaming, Intervention, Avatar Customization, Social Phobia

\section{ACM Reference format:}

Dechant Martin J., Birk Max V., Shiban Youssef, Schnell Knut, and Mandryk Regan L.. 2021. How Avatar Customization Affects Fear in a Game-based Digital Exposure Task for Social Anxiety. In Proceedings of the ACM on Human-Computer Interaction, Vol. 5, CHI PLAY, Article 248 (September 2021), 27 pages, https://doi.org/10.1145/3474675

\section{INTRODUCTION}

Social anxiety is characterized by the fear of being evaluated by others [114], which pushes affected individuals to avoid or withdraw from social interactions, and leads to elevated stress when social interactions are not avoided [6,153]. However, the fear of evaluation within social situations stands in opposition to the universal human need to form and maintain meaningful

Author's addresses: Martin J. Dechant, martin.dechant@usask.ca; Max V. Birk: m.v.birk@tue.nl; Youssef Shiban shiban@pfh.de; Knut Schnell knut.schnell@med.uni-goettingen.de; Regan L. Mandry regan.mandryk@usask.ca

Permission to make digital or hard copies of all or part of this work for personal or classroom use is granted without fee provided that copies are not made or distributed for profit or commercial advantage and that copies bear this notice and the full citation on the first page. Copyrights for components of this work owned by others than ACM must be honored. Abstracting with credit is permitted. To copy otherwise, or republish, to post on servers or to redistribute to lists requires prior specific permission and/or a fee. Request permissions from Permissions@acm.org.

Copyright $\odot$ ACM 2021 2573-0142/2021/9 - Art248 \$15.00

https://doi.org/10.1145/3474675 
relationships [141,157]. Social anxiety is one of the most common mental illnesses and is highly prevalent world-wide [60,154], especially affecting children and adolescents [77,123]. Given the social inhibition and withdrawal of affected individuals, social anxiety symptoms are often mistaken for shyness by others or perceived as a character flaw by the individual [124]. Furthermore, due to the characteristic fear of negative or positive evaluation by others, individuals with social anxiety may avoid consulting mental health workers about their concerns [91]. Prior work shows that only $35 \%$ of individuals who are affected by social anxiety receive treatment [139]. Besides the challenges of the mental illness, other barriers [88], such as sociocultural (e.g., discrimination of mental health problems) [7], economic (e.g., lack of financial coverage for mental health interventions) [43], or geographical barriers (e.g., limited access in remote communities) [30] may lower the accessibility of treatment and interventions.

A large body of literature supports cognitive behavioral therapy (CBT) as an effective nonpharmacological treatment for social anxiety $[8,69,103]$. CBT includes different components in sessions guided by a therapist (e.g., psychoeducation, cognitive restructuring) as well as selfguided assignments (e.g., worksheets and homework exercises) for the patient. One central treatment component of CBT for social anxiety is controlled exposure [56], in which the patient faces feared stimuli in a safe environment to challenge their thoughts about the stimulus and to train less maladaptive behaviour [136]. Through different exposure techniques, such as "in vivo" exposure (e.g., roleplaying with the therapist) or "in virtuo" approaches, such as using immersive virtual reality $[28,34]$, the patient interacts with the feared object (e.g., a spider) or in a simulated context (e.g., a social encounter). Exposure therapy is thought to help the patient in several ways, including through habituation (decrease the reaction to feared stimuli), extinction (weakening of previously learned assumptions about the stimuli), self-efficacy (training how to behave in an encounter with the feared stimuli), and improved emotional processing (gaining new beliefs about feared stimuli) [160]. Digital exposure therapies are a particularly promising technology to tackle the rising need for the treatment of anxieties and phobias, as they offer equitable access, regardless of geography or income, can be tailored for individual patients, and scale better in terms of needs than in vivo exposure therapies [162].

Although virtual exposure therapies have been shown effective at treating a variety of anxiety disorders and phobias (e.g., arachnophobia, fear of heights, agoraphobia, claustrophobia $[25,26,47,149])$, social anxiety may be more challenging to treat with in virtuo exposure using digital technologies. Cognitive models of social anxiety suggest that an effective exposure needs to simulate an audience, the perception of negative evaluation by an audience, and the perception that it is the patient themselves who is being evaluated. However, the feeling of being evaluated by others can be difficult to achieve in a digital simulation, because participants may not be completely immersed or believe in the simulated content. Prior work shows that the behaviour of the simulated audience is more essential than the visual representation [121,151]. However, the accurate simulation of these behaviours may become a challenge within the development of digital interventions due to the more complex nature of the simulation (e.g., a convincing implementation of a rejection gesture or facial expression). To be effective, an exposure therapy for social anxiety must completely engage the patient, capturing their focus [58] and engaging them enough to invoke increased arousal and anxiety [70]. Because exposure is an uncomfortable experience, patients sometimes cope by cognitively disengaging, diverting their attention, or distracting themselves [70]. As such, an exposure task must maintain the patient's attention and focus over the duration of the exposure [168], perhaps by being sufficiently engaging, attentionally demanding, or through mechanisms that increase their investment in the experience. Further, the 
exposure needs to remain salient for long enough to support cognitive reframing (via habituation, extinction, self-efficacy, or emotional processing). Finally, the user needs to repeatedly feel as if they are being actively judged, which can be difficult to achieve in a system where they are represented by an avatar and other participants are simply virtual representations.

Video games are digital contexts in which players are often represented in the world by an avatar, and in which their interactions with the environment and with other players and non-player characters in the environment often generate emotional responses (e.g. [40]), physiological responses (e.g., [101]), and social interactions (e.g., [75,86]) that are as intense and real as those that take place in the physical world. Games are known to capture attention [142] through cognitive, emotional, physical, and social demands [27]. Further, previous work has shown that harnessing the game-based technique of avatar customization is one way to increase engagement with a system: avatar customization has been shown to increase identification with the avatar (and resulting engagement with the system) not only in digital games [98], but also in serious games [17], and in therapeutic scenarios [21]. In the context of social anxiety, customization may elevate the experience of fear in a social simulation that involves performance and potential judgement from others. The inner conflict between the mental self-representation and perceived social norms may be intensified through an elaborated self-representation, which would justify how an audience evaluates not only the person's performance, but also the appearance or characteristics of the avatar. Early evidence within the context of virtual reality simulations, in which the face of participants was mapped onto an avatar, showed that individuals experienced higher levels of social anxiety if they saw a character with a mapped photo of their face as the facial texture [10]. However, systems for large-scale exposure therapy may not be able to represent the participant at a high fidelity, so the question remains: Does customization of selfrepresentation increase expected and experienced fear within an in virtuo digital exposure task for social anxiety?

In this paper, we conducted an online experiment with 200 participants in which participants had to complete a task inducing social stress. In four trials, participants controlled an avatar through a virtual shop. In this shop, they had to solve a math problem at the checkout counter, while a simulated audience within the virtual world observed them and negatively judged their performance. Before the exposure, we randomly assigned participants into two groups: one with predefined avatars and one in which they were asked to design their own avatar representation using a customization tool. We estimated the participant's level of social anxiety using the Liebowitz Social Anxiety Scale (LSAS), a commonly used tool for subjectively assessing social anxiety in the clinical context, and we measured both the subjective expected and experienced fear score for each of the four repeated exposures. Further, we used the Player-Identification Scale (PIS) to measure the participants' identification with their avatars and explored whether the customization amplifies the relationship between social anxiety and fear (both expected and experienced). We further explored whether customization helps prevent instant habituation within an immediately repeated exposure.

We show that we can stimulate the fear of evaluation by others in a digital task that is inspired by game interactions. Our results suggest that participants who customized their avatar experienced higher identification, and that the elevated levels of expected and experienced fear stemming from customization were driven by those participants highest in trait social anxiety. Additionally, we show that the level of stimulated fear corresponds with trait social anxiety, and that this relationship between trait social anxiety and fear is amplified for those who used customized avatars as opposed to predefined avatars. We further inspected the changes in experienced fear 
over repeated iterations and found that customized avatars may help maintain fear over multiple exposures, although longer-term studies are needed. We discuss potential explanations of why avatar customization increases the manifestation of social anxiety in a web-based exposure, and how this may benefit digital exposure therapies for social anxiety. Additionally, we contribute suggestions on how customization may be applied in a gradual exposure to increase the efficacy of an exposure therapy while lowering entrance barricades (e.g. fear of being overwhelmed by the procedure [135]) to the exposure therapy,

Through this paper, we contribute evidence that customizing avatars can amplify the experience of fear in a digital game-like exposure-a necessary condition for efficacy in the development of a virtual therapy to treat social anxiety.

\section{RELATED WORK}

This research analyses whether the player's representation affects the experience of social anxiety within digital applications, which may be an essential component in the development of digital interventions.

\subsection{Characteristics of Social Anxiety}

One of the defining characteristics of social anxiety is the fear of social interactions due to the exposure to potential scrutiny from others [70,85,145]. As a consequence, socially-anxious individuals withdraw from these fear-inducing social interactions, sometimes accompanied by physical symptoms such as blushing, heavily trembling, or sweating [1]. With a prevalence of 2.0 $\%[53,54]$ in the general population, social anxiety is one of the most prevalent anxiety disorders. The severity of social anxiety is best expressed on a severity continuum where one can experience a high degree of social anxiety but not reach the threshold for a clinical diagnosis [153]. Individual factors (e.g., genetics, temperament and cultural background) and contextual factors (e.g., the social context and the physical environment) affect an individual's likelihood of developing social anxiety. Due to the high variability of individual and contextual factors, the experience of social anxiety varies. A person might, for example, experience high levels of social anxiety only when presenting in an unfamiliar context (e.g., a talk at a conference), whereas the same person experiences less distress when presenting in a familiar environment (e.g., in front of family members).

Socially-anxious individuals face greater difficulties maintaining relationships with others [130]. Therefore, affected individuals tend to have fewer close friends [150,163], and are at higher risk of being rejected by their peers. Furthermore, they may be at higher risk of being victimized by others due to the potential deficiencies in social competence [109]. Previous research emphasizes adolescence as a critical phase for the development of social anxiety [39]. If untreated, social anxiety follows a chronic and unremitting course through the lifespan. As a result, social anxious individuals may adapt coping strategies with known negative effects, such as substance abuse [164] and social withdrawal [167], or may develop clinical levels of social anxiety or comorbid mental disorders, such as depression $[115,155]$. The harmful consequences of social anxiety also extend beyond the individual, due to a higher risk of unemployment [42] and absenteeism from work $[49,159]$ among the socially anxious, which may increase the financial dependency on public support systems [159]. However, due in part to the fear of evaluation by medical professionals, many socially-anxious individuals never seek treatment $[43,76,91]$. 
As previous work introduced, social anxiety is thought to be more cognitive in nature $[70,130,131,145]$ compared to other specific anxiety disorders, which are based in the interaction with either certain animals [24,149] or physical aspects of the world, such as height or space $[47,126,128]$ : Cognitive models of social anxiety $[37,70,71,145]$ depict this anxiety as a reaction to a mismatch between the individual's cognitive self-image, and the perceived expectations of the surrounding social context [70]. Socially-anxious individuals tend to overestimate the expectations of social observers and fear that they will not satisfy these high standards [72,73]; biased by previous 'failures', they are quick to judge that a social interaction or performance in front of others will go poorly [29]. The effects of social anxiety are explained by emotional processing theory $[58,106]$, which describes dysfunctional fear as a memory network comprising information about the feared stimulus, the fear response, and propositions of meaning. This network can be (partly) activated by matching inputs, which results in an experience of fear. There are at least two activation paths explored: the perceptual (e.g., visual-fear-related cues) and the conceptual (i.e., fear-related information) path. Previous research [46] shows that patients with specific phobias (e.g., spider phobia) seem to be particularly sensitive to perceptual activations (e.g., seeing a spider), while socially-anxious individuals were not. Furthermore, cognitive models [37,70] of social anxiety highlight several aspects for a successful exposure, which require information cues and perceptual cues. In these models, social anxiety is depicted as a reaction to a mismatch between the patient's own cognitive self-image, and the perceived social expectations of a given context. Socially-anxious individuals tend to be concerned with how they may fit into the existing context, rather than their own actual performance [23]. Therefore, the models suggest that an effective exposure needs to stimulate not only the perception of an audience but also the perception of negative or positive evaluation by others, depending on the characteristics of social anxiety for a specific individual.

\subsection{Digital Interventions for Social Anxiety}

Besides medication that reduces the symptoms of anxiety [103,120,169], cognitive behavioural therapy (CBT) has shown consistently positive effects on reducing symptoms of anxiety $[103,137,152]$ and providing long-term relief for affected individuals [92]. In comparison to medication, psycho-social intervention strategies have fewer side-effects [103] and the likelihood of relapses because they teach patients flexible cognitive strategies. Exposure therapy in particular has shown consistent positive treatment effects and is considered one of the most efficient treatment strategies for anxiety [116]. Trained experts expose patients to either "in vivo" (e.g., roleplay) [165] or "in virtuo" (e.g., imagination) [35] anxiety-inducing situations, and guide patients to restructure their cognitive responses [64] and gain control over their physiological responses [66].

Although effective, CBT approaches face several limitations stemming from geographical restrictions and available resources but also the requirement for individualized content due to the characteristics of social anxiety (e.g., presenting in front of a large audience) [14]. Further, being with a mental health professional itself can become a stressful experience for socially-anxious individuals due to the fear of being negatively judged by the professional [76,91]. Digital solutions have shown promise in lowering access barriers: immersive media, for example, allows patients to experience anxiety-inducing situations which the therapist can control and manipulate in virtuo, i.e., in virtual reality. Through immersive media, the experience reduces the cost [32] but also increases the patient's feeling of safety [34]. 
A similar option to deliver treatments are Internet-Mobile-based Interventions (IMI) [50,81]. IMIs promise to lower barriers of access to interventions by offering anonymous, flexible, and effective treatment options. IMIs guide patients through experience either guided with a mental health professional or they offer unguided help to help patients with their anxiety symptoms [15]. However, research shows that while digital solutions are promising in research studies, the effects are diminished in the wild, because participants are not using technology as required, e.g., participants stop using the technology after a period of time [2,52]. High levels of attrition undermine even the best designed approach, because participants simply do not use the intervention.

However, intervention adherence, either digital or traditional, has been shown to be instrumental for the effectiveness of almost every intervention protocol, e.g., taking medication, following a diet, and/or executing lifestyle changes [144]. To combat attrition and to increase training adherence, designers rely on a variety of methods such as peer-support, and oral or written contracts [138]. Considering the interactive nature of IMIs, their potential to respond to individual differences [111], and their flexibility in protocol and presentation, IMIs show promising characteristics to help intervention designers combat attrition through design [22].

Several approaches for sustaining interest and engagement have shown promising results: notifications have increased the return of clients in the short-term [74] and interface design strategies based on game-based techniques have increased user engagement [97]. Prior research shows that the lack of personalization, interactivity, and support, increases the risk for attrition for mental health apps [5]. Due to their engaging nature and the high potential to define interactive scenarios, video games and the use of game-design approaches within the intervention context have received attention by intervention designers [100].

To keep players engaged in the long-term and focused in the short-term, avatar customization has been shown to be a promising interface manipulation that reduces attrition in IMIs [22]. While positive results have been shown for increasing engagement in a variety of interventions (see next section), the use of customized avatars for improving exposure therapy for social anxiety has not yet been explored.

\subsection{The Positive Effects of Avatar Customization}

As previously introduced, the perception of being with other individuals is a key component for the experience of social anxiety. During exposure therapy patients are exposed, either in vivo or in virtuo, to a fear inducing situation with the goal to train less harmful responses as well as to help patients to restructure personal thoughts about the situation.

Avatar customization promises three advantages over design strategies that assign an avatar to a patient. First, avatar customization increases identification with the avatar [20,21], which may increase the perception that it is the patient themselves who is being evaluated [70]. The degree we are identifying with an avatar-commonly measured using the Player Identification Scale (PIS) [99]-is predictive of play experience [62,95,98], time spent in a game [21], and enjoyment [68]. The PIS measures similarity identification, wishful identification, and embodied identificationwho we are and how we feel represented in a game influences our experience $[18,118]$.

Second, avatars can increase the experience of social presence, which is particularly relevant when designing IMIs focused on training resilience to situations known to trigger social anxiety [55]. Previous work on avatars and social presence suggests that dissimilar avatars reduce anxiety [10] compared to similar avatars. The implications of avatars on behaviours and attitudes in and outside of virtual worlds has been shown in several studies [84,173], and a meta-study confirms 
small-to-medium effect sizes [132]. Avatars have been used to reduce anxiety, e.g., by destroying a carefully created "anxiety" avatar as an intervention [122] or to reduce speech anxiety [9]. On an individual level, avatars can model behaviour and represent different user-states well. In online environments, they fulfil an important role to foster a sense of presence for the "owner" of an avatar, but also provides affordances for other players to interact with the avatar "owner". In social contexts, avatars have been shown to increase presence and foster trust [16], and are valued by players for several social characteristics, including sociability and social communication [98]. Non-player characters, such as bystanders in games, affect our player experience and the believability of game worlds and contribute to the experience of presence in a game $[11,31,90]$.

And third, avatar customization has the potential to increase momentary engagement [22], potentially improving the patient's attention and focus during the intervention [37,58]. Avatar customization has been shown to increase task engagement, and the efficacy of digital tasks that benefit from momentary focus [22]. Previous work suggests that avatar customization increases the experience of acting under our own volition [146] and alters how we experience play [171], but that the experience of autonomy is mediated by individual differences such as self-esteem [166]. Across studies, avatar customization has been shown to have positive effects on engagement with a task, which is relevant in studies that rely on participant engagement to investigate differential effects of design elements.

As shown, avatar customization may offer great potential in various directions for games but also for digital mental health interventions. However, prior work strongly emphasizes several aspects that designers need to be aware of in the process of creating avatar customization interfaces [104], such as the selection of gender, skin colour, the amount of customization, as well as to increase ways to create non-binary and diverse avatars [104,105]. Furthermore, prior research highlights the overwhelming desire for more diversity within the self-representation in-game [61].

In the context of our study, avatar customization is the primary manipulation of the experience. By enabling participants to customize their avatar, we aim to intensify the experience of social anxiety within the exposure task. Furthermore, the representation of observers through nonplayer characters (NPCs) is also relevant, as bystanders increase social pressure and induce judgement from an audience.

\section{METHODS}

\subsection{Exposure Task and Experimental Conditions}

\subsubsection{Avatar Customization}

Prior to the task, participants were randomly assigned (between-subjects) to either a Predefined Character or a Customized Character (see Figure 1):

Customized Character: In this condition, participants could adjust the appearance of their avatar. Participants first selected the gender of their avatar (woman or man), then adjusted the height, weight, muscles, head offset, and breast size as well as the skin colour, eye colour, hairstyle (11 different styles per gender), and hair colour of their avatar. Due to technical limitation of the framework used for the character design process, a non-binary representation could not be created. Participants could then shape the head of their avatar via 34 sliders to define the shape of the face, eye, brows, nose, mouth, chin, jaw, ear, neck. Next, participants could choose the outfit of their avatar by choosing the style and colour of clothing on the upper body, lower body, and shoes, as well as through head accessories, such as glasses, headphones, or hats (13 different 
options per element). To further increase the player's identification with their avatar [99], we asked participants to set the personality of their avatar, by adjusting five 7-point Likert scales, which each described one personality trait, based on the 10-item short version of the Big Five Inventory (BFI-10) [129]. The 10 items were paired into 5 categories and participants had to choose between the elements (e.g., anxious versus calm).

Predefined Character: In this condition, participants could choose the gender representation of their avatar. However, all other characteristics were pre-selected by the system to be as generic as possible (e.g., mid-tone hair colour, mid-tone skin colour, generic clothing, no accessories, midrange slider values) and could not be customized. Average options were chosen to most broadly represent a range of people using a single predefined character. Participants were asked to focus on the selected predefined character, once they were finished with the selection.
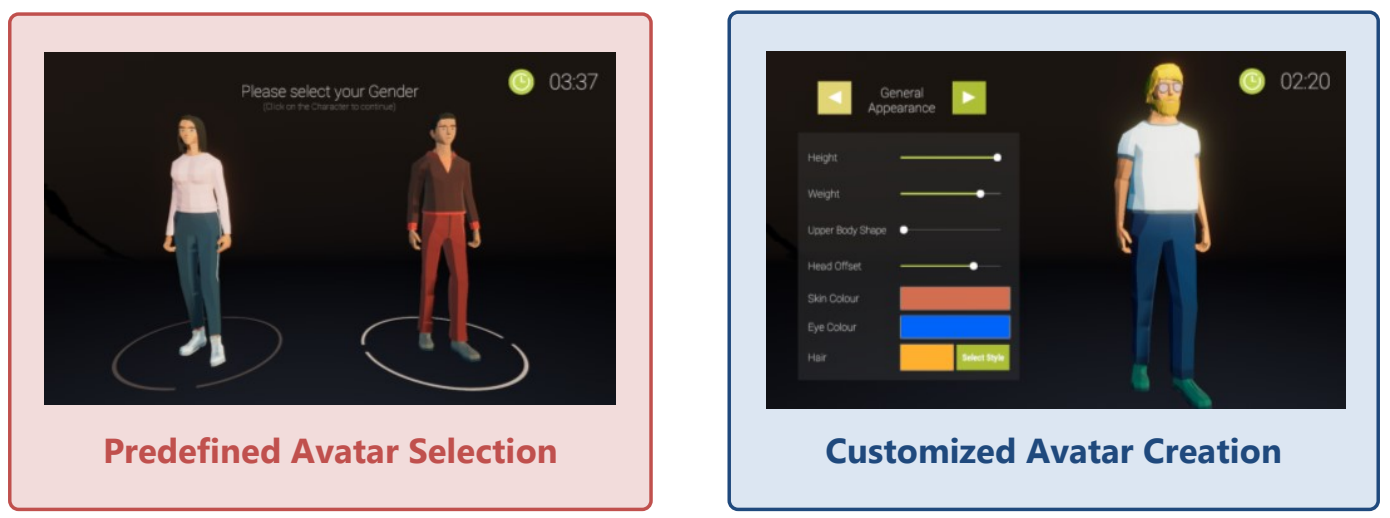

Figure 1: Avatar Creator User Interface for the Selection of Predefined (left) and Customization of Player's Avatar

To make sure that exposure to the avatar did not bias results, both groups had to spend at least four minutes inside of the character creator. After four minutes, participants could move on to the next step of the experiment by clicking a button on the screen.

In both avatar conditions, participants were asked to answer the Player Identification Scale (PIS) [99] to determine how much participants associated their avatar with themselves on three dimensions: Similarity, embodied, and wishful identification. Because there are limitations of the character creator to fully represent all people, such as the lack of a non-binary gender option and limited selection of headgear or hair styles, we gathered avatar identification to help explain variance when participants may have felt they were limited in their self-expression.

\subsubsection{The Shopping Task (Exposure)}

To create a relatable experience that has commonly been reported as anxiety inducing by people with social anxiety, we created a virtual grocery store and designed an interactive purchase scenario (Figure 2). This scenario is based on the Trier-Social-Stress-Test (TSST) in which participants have to present in front of an audience of judges [4]. Participants were instructed to go to the check-out of the store. Participants controlled their avatar using the keyboard (WASD or arrows), and the mouse to control the camera. The scenario featured three non-player characters (NPCs): the cashier, and two observing characters marked with "Observer" tagged with a random number to indicate different observers per round, as well as an icon indicating their emotional state (see Figure 2). The two observers were included to add an element of social evaluation to the 
exposure task, as potential social evaluation by others plays an essential role for the experience of fear. These observers were introduced as representations for other human observers, observing the participant through a text notification in the beginning as well as a separate screen, which indicates that external observers are joining the session. Prior work suggests that the social stress effect of being observed is also present with two instead of the three observers of the original TSST [48].

We decided to have participants virtually purchase a product associated with potential embarrassment (toilet paper) [94] to foster a situation that would be likely to induce an experience of social anxiety. The players only interacted with the cashier. Once they approached the cashier (the toilet paper was visible at the checkout), a dialog would start:

Cashier: "How many roles of toilet paper do you want to buy?"

After answering the question with a number, the cashier names a price and offers a percentage discount that the player needs to calculate and respond to within 8 seconds.

Cashier: "Thank you very much. That costs \$ 86.45. But today we offer you a discount of $8 \%$. Could you help me and name the price for your purchase?"

During this interaction, the observers are visible, responsive, and are watching the participant complete the task. Similar to previous work, we selected a task to simulate the experience that participants have to perform a hard task in front of other individuals (the observers) [44,125]. We chose a math task because math has shown to be relevant for our self-perception [36] and is a known source of performance-based anxiety [59]. We chose an 8-second window, as it was too short to use an external calculation tool, but long enough to be answerable.

While the calculation was chosen to be difficult, independent of the answer being correct or not, the player receives a negative response by the cashier and the NPCs after entering a number. The cashier shows no reaction to the player's performance and looks towards the player's avatar. The NPCs are facing each other while the player approaches, but both turn towards the player while they answer the math question and show a 5-second animation of disappointment once an answer has been given. The price and discount were randomly selected per trial.

In total, participants played through the shopping task four times. As previous work suggested [44], the four trials were included to evaluate how repeated exposure affects the experience of social anxiety in an online task, and to determine whether or not participants habituated to the exposure.
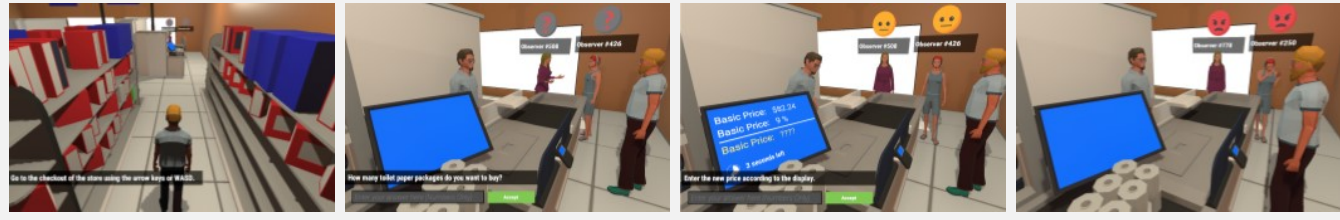

Figure 2: The four steps of the task (from left to right: Approach the situation; Introduction to problem; Math riddle; Exposure)

The task was implemented using Unity Engine [158] combined with the Asset-Bundle "Advanced People Pack 2" [93] and deployed using the Bride of Frankenstein framework [79]. The Advanced People Pack 2 offers prepared 3D-objects with blend-shapes, which allow to adjust the body shape (weight and muscularity) and the skin colour. These 3D objects are mapped either to the basic shape of either a female or male character. The characters implement blend-shapes as well to 
manipulate different features of the face. Based on these 3D assets, we created our character editors that allow for customization based on the previously introduced conditions.

\subsection{Participants and Procedure}

We deployed our experiment to participants recruited using Amazon's Mechanical Turk (MTurk). MTurk is an online platform where Human Intelligence Tasks can be posted by requesters and workers can opt-in to complete them. Data collected from MTurk has been successfully used for different research projects in the human-computer interaction (HCI) community $[45,80,119]$. But this approach reqfuires some special care to ensure that bots or negligent workers are removed from the final analysis [67]. Participants who were not able to perform a 3D interaction task on their computers, as well as those who abandoned the experiment were excluded from analysis. For this experiment, we used the cover story that the experiment aims to explore the effects of gamified elements in an immersive shopping experience. The cover story was used to reduce the risk that participants behaved differently (e.g. white coat hypertension [147]) as a result of knowing the goal of the study. This experiment as well as the usage of the cover story was approved by Ethics board of the University of Saskatchewan. The real intention of the study was revealed in the debrief of the study. Requesters can invite participants based on given filters on the MTurk platform, such as demographics, prior work experience as well as the used technology and custom filters (e.g., if participants participated in prior work). For this study we recruited participants, who indicate that they live either in Canada or the United States of America as well as have a high approval rate (95\%) and successfully participated in at least 100 other tasks before. We collected data from 213 participants. After removing suspected bots $(\mathrm{n}=13)$, we conducted our analysis with the remaining 200 participants (72 woman, 126 men, 2 non-binary) aged 21-70 ( $\mathrm{M}=$ 36.6, $\mathrm{SD}=9.6$ ). Participants were randomly assigned to either the "Predefined Character" condition, $\mathrm{n}=102$; or the "Customized Character" condition, $\mathrm{n}=98$ (See Table1 for further details). All participants received $\$ 6$ compensation; the study took approximately 20 minutes to be completed.

After providing consent, participants were introduced to the cover story and had to answer several questionnaires to assess trait social anxiety as well as several questionnaires about the shopping preferences to distract users from the main goal of this study. After finishing the avatar creation/selection participants had to answer the Player Identification Scale (PIS) [99]. Following this, we introduced the controls and that external observers would evaluate the participants performance via a text tutorial. As prior introduced, we further emphasised the illusion of being watched by showing a loading screen that indicated a waiting period while observers were being connected to the current session with the participant. This screen lasted for 5 seconds before the tasks started. Four repeated trials of the shopping exposure task were conducted using randomized values for the percentage discount and the asked price. Expected fear was assessed prior to each trial and experienced fear was assessed directly following each trial. After the trials, demographic data were recorded and participants were debriefed about the false cover story and the real goal of this study. Then, we provided additional support resources such as contact information to a crisis hotline, and a link to pictures of baby animals to reduce the potential negative effect on participants. 


\subsection{Measures}

\subsubsection{Trait Social Anxiety}

Participants answered the self-report version of the Liebowitz Social Anxiety Scale (LSAS) [12,96]: The LSAS consists of 24 items divided into two subscales: social interactions (11 items) and public performance (13 items). The same items are then rated a 4-point scale for fear $(0=$ "none" to $3=$ "severe") and avoidance ( $0=$ "never/0 \%" to $3=$ "usually/68-100 \%"). The sum of all scores is computed and the level of social anxiety defined between 0 and 144, where higher values indicate greater social anxiety. A threshold score of 30 distinguishes between non-anxious and anxious people while a score of 60 provides the best balance to classify between generalized and nongeneralized social anxiety [143]. In our sample, LSAS scores ranged from 0 to $141(\mathrm{M}=58.95, \mathrm{SD}=$ 31.403 ) with an excellent internal consistency (Cronbach's- $\alpha=0.97$ ). LSAS was higher on average in our sample than in a study of 31,243 cross-cultural participants $(M=44.07)$ [33] or in a study of 1007 UK college students $(M=34.7)$ [140], but is in line with previous work examining a US MTurk sample $(\mathrm{M}=51.24)$ [45].

\subsubsection{Avatar Identification}

We used the avatar-related subscales of similarity identification, embodied identification, and wishful identification from the Player Identification Scale (PIS) [99]. Participants rated their agreement to different statements such as "My Character is like me in many ways" on a 5-pt Likert Scale from 0 ("strongly disagree") to 4 ("strongly agree"). As previously introduced, avatar identification is an important aspect for the various effects of avatar customization [22,98]. Internal consistency was excellent for all scales: similarity (Cronbach's- $\alpha=0.93$ ), embodied (Cronbach's- $\alpha=0.94$ ), and wishful (Cronbach's- $\alpha=0.90$ ) identification.

\subsubsection{Expected and Experienced Fear Ratings}

We asked participants to rate their expected fear prior to being exposed to the shopping task using a single text field and the following prompt: "In the following scene you have to buy some groceries in a virtual shop. Other people will join you in this task and evaluate your performance. Please indicate on a scale from 0 (not at all) to 100 (very high level of fear) how much fear you feel in expectation of completing the described task.".

Experienced fear was assessed after exposure to the Shopping Task, using the following prompt: "Please indicate on a scale from 0 (not at all) to 100 (very high level of fear) how much fear you actually felt in completing the task.".

\subsubsection{Demographics}

We gathered a variety of demographic factors, including: age, gender, income, marital status and ethnicity.

\subsection{Data Analyses}

Data were gathered and stored using an on-premises server and then exported once data collection was complete. All data were analyzed using SPSS 26; moderated regressions used the Process 3.4 integration. Statistical tests are described prior to reporting the results. 


\section{RESULTS}

\subsection{RQ0: Characterizing the Sample}

We first looked to see whether random assignment to condition yielded differences between the groups. Independent-samples t-tests showed that there was no difference in terms of age $\left(\mathrm{t}_{198}=.954, \mathrm{p}=.341\right)$ or LSAS $\left(\mathrm{t}_{198}=.558, \mathrm{p}=.577\right)$. Both were slightly skewed in terms number of men (see $\mathrm{xx}$ ) We control for age and gender in all subsequent analyses.

Table 1: Overview per condition of demographic information, LSAS, and PIS measurements.

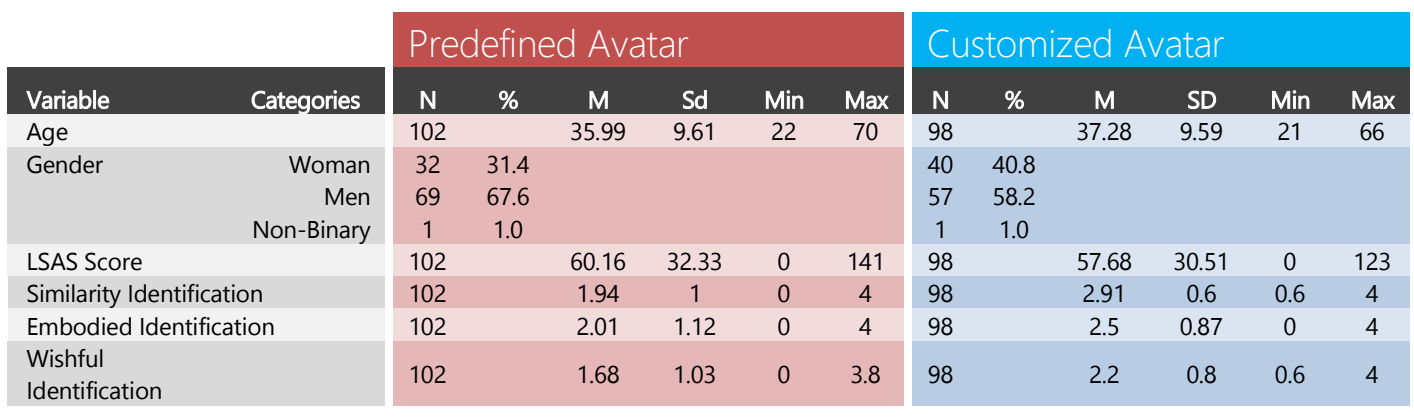

\subsection{RQ1: Can We Confirm that Customization Increases Avatar Identification?}

Based previous work (e.g.,[18,22,117]), we expected to see higher avatar identification among the group who were able to customize their avatar, as opposed to being assigned a predefined generic avatar. To confirm whether these effects appear in our sample we used a MANCOVA on similarity, wishful, and embodied Identification with avatar customization as a between-subjects factor and co-variates of age, gender, and LSAS, which was significant $\left(\mathrm{F}_{3,193}=26.0 ; \mathrm{p}<.001\right.$, $\mathrm{p} \eta^{2}=.29$ ). Results showed that identification was higher for customized than predefined avatars in term of Similarity $\left(\mathrm{F}_{1,195}=68.3 ; \mathrm{p}<.001, \mathrm{p} \eta^{2}=.26\right)$, Wishful $\left(\mathrm{F}_{1,195}=22.9 ; \mathrm{p}=.001, \mathrm{p} \eta^{2}=.05\right)$, and Embodied $\left(\mathrm{F}_{1,195}=11.2 ; \mathrm{p}<.001,{ }_{\mathrm{p}} \eta^{2}=.11\right)$ identification. This suggests that even though avatars were low-poly graphics, our avatar customization manipulation was successful at fostering identification among participants.

\subsection{RQ2: Does Customization Amplify the Relationship between LSAS and Expected Fear?}

We expected that participants who used a customized avatar would have a stronger relationship between LSAS and the fear that was expected prior to an exposure. A moderated regression with $\mathrm{X}=\mathrm{LSAS}, \mathrm{Y}=$ mean expected fear, $\mathrm{W}=$ dummy-coded condition (Customized=1, Predefined=-1), with continuous variables mean-centered, and controlling for age, gender, and the three forms of avatar identification shows a significant model (R2=.318, F8,191=11.1, $\mathrm{p}<.001)$. The significant effect of LSAS $(\beta=.350, \mathrm{p}<.001, \mathrm{LLCI}=.232$, ULCI $=.468)$ shows that LSAS predicts expected fear. The effect of customization on prediction of expected fear is not significant $(\beta=-7.5$, $\mathrm{p}=.059$, LLCI=-15.3, ULCI=-0.3), suggesting that at mean LSAS, the increased fear from customizing fails to reach significance. However, the significant interaction of LSAS and customization on expected fear $(\beta=.128, \mathrm{p}=.026, \mathrm{LLCI}=.016, \mathrm{ULCI}=.241)$ suggests that the prediction of expected fear by LSAS depends on customization. The conditional effects show that the linear relationship between social anxiety and expected fear is larger for customized avatars 
$(\beta=.479, \mathrm{p}<.001, \mathrm{LLCI}=.310, \mathrm{ULCI}=.647)$ than for predefined avatars $(\beta=.222, \mathrm{p}=.006, \mathrm{LLCI}=.065$, $\mathrm{ULCI}=.379$ ). Figure 3 shows these relationships.
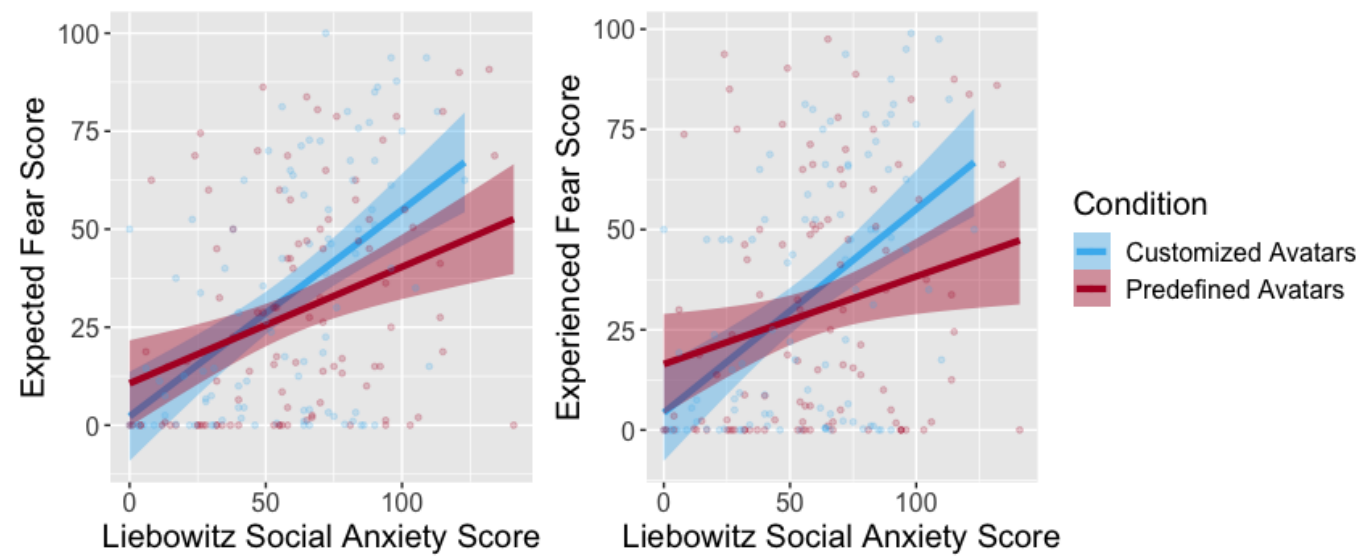

Figure 3: The comparison between predefined (red) and customized (blue) avatars for expected and experienced fear.

\subsection{RQ3: Does Customization Amplify the Relationship between LSAS and Experienced Fear?}

We expected that participants who used a customized avatar would have a stronger relationship between LSAS and the fear that was experienced during an exposure. A moderated regression with $\mathrm{X}=\mathrm{LSAS}, \mathrm{Y}=$ mean experienced fear, $\mathrm{W}=$ dummy-coded condition (Customized=1, Predefined=-1), with continuous variables mean-centered, and controlling forage, gender, and the three forms of player-avatar identification shows a significant model $(\mathrm{R} 2=.272$, $\mathrm{F} 8,191=8.92, \mathrm{p}<.001)$. The significant effect of LSAS $(\beta=.279, \mathrm{p}<.001, \mathrm{LLCI}=.150, \mathrm{ULCI}=.409)$ shows that LSAS predicts experienced fear. The significant effect of customization on experienced fear $(\beta=-10.1, p=.022, \mathrm{LLCI}=-18.6, \mathrm{ULCI}=-1.5)$ identifies that at mean LSAS, experienced fear is higher in the customized avatar condition than in the predefined avatar condition (because LSAS was mean-centered). The significant interaction of LSAS and customization on experienced fear $(\beta=.153, p=.016, \mathrm{LLCI}=.029$, ULCI $=.276)$ shows that the prediction of experienced fear by LSAS depends on customization. The conditional effects show that the linear relationship between social anxiety and experienced fear is larger for customized avatars $(\beta=.432, \mathrm{p}<.001$, LLCI $=.247$, $\mathrm{ULCI}=.617)$ than for predefined avatars $(\beta=.127, \mathrm{p}=.150$, LLCI $=-.046, \mathrm{ULCI}=.299)$, which does not reach significance. Figure 3 (right) shows these relationships.

\subsection{RQ4: Does customization help prevent immediate habituation within repeated exposure?}

For digital exposure therapy to be a successful treatment, the virtual exposure needs to maintain its capacity to produce a fear response in people with that anxiety. That is, there cannot be instant and rapid habituation to the virtual stimuli; habituation happens over time through repeated exposure and cognitive restructuring (see Related Work). If habituation is instant, it implies that stimuli is failing to evoke a fear response, not that the treatment has been instantly successful. Figure 4 shows the mean expected fear response over each of the 4 iterations for participants with 
LSAS over 60 (the threshold used to indicate social anxiety [143]), whereas Figure 4 (right) shows the mean experienced fear over the four iterations for this same group. In all cases, there is not a rapid drop after the initial exposure. In terms of expected fear, both customized and predefined avatars follow the same trend with decreasing differences in fear from one iteration to the next. This suggests that participants are getting more comfortable with their expectation of fear from the exposure. In terms of experienced fear, the mean ratings for the group using customized avatars is monotonically increasing; however the mean ratings for the group using predefined avatars is decreasing over several iterations. Although preliminary, and based only on visual inspection, these results suggest that there is no instant habituation in either condition, or that customizing avatars may help maintain fear within the exposure over multiple iterations; however, more research is needed to systematically investigate fear responses over time.
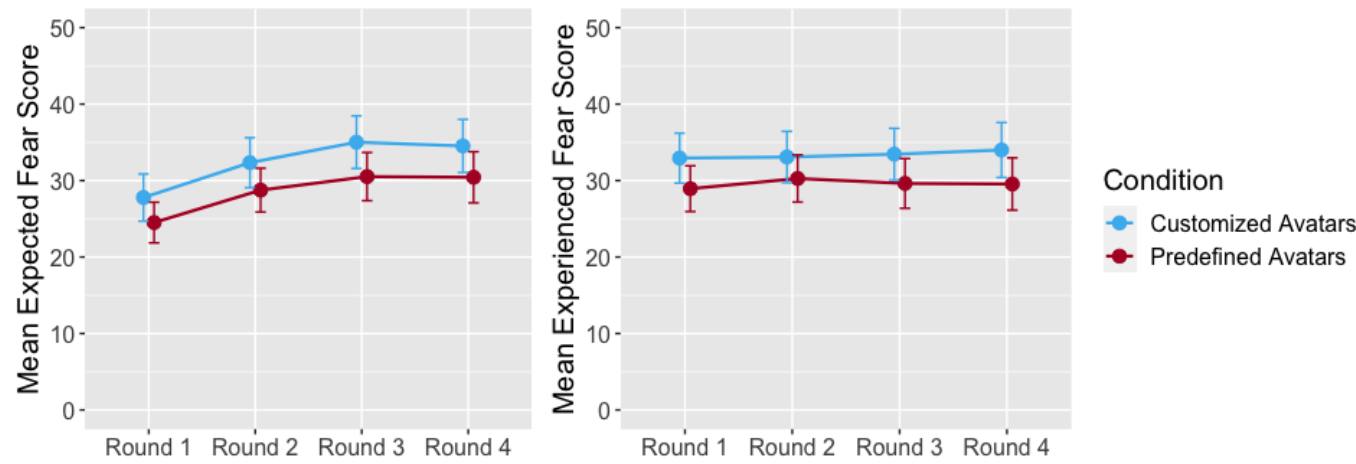

Figure 4 The mean score of expected and experienced fear over the four exposure rounds, for participants with LSAS > 60 (threshold for elevated social anxiety [143]).

\section{DISCUSSION}

\subsection{Summary of the Results}

In this study we evaluated the effects of avatar customization on the experience of social anxiety in a task that induces social stress. We found the following results:

- RQ1: Customization of the avatar results in increased feelings of similarity, wishful, and embodied identification in comparison to using a predefined avatar.

- RQ2: LSAS predicts expected fear scores; however, the strength of this prediction is larger when participants customized their avatar.

- RQ3: LSAS predicts experienced fear scores; however, the strength of this prediction only reaches significance when participants customized their avatar.

- RQ4: Preliminary evidence suggests that customized avatars may help maintain fear within the exposure over multiple sessions more effectively than with predefined avatars.

Overall, participants expected, and experienced, fear in this web-based exposure task for social anxiety. Furthermore, customizing the self-representation heightened the experience of fear, in particular for those higher in trait social anxiety. Also, visual inspection shows that the experience of social anxiety does not drop over time, suggesting that the sensation of fear may be maintained over multiple exposure trials. 
In the following we provide potential explanations of why avatar customization increases the manifestation of social anxiety in a web-based exposure, and how this may benefit digital exposure therapies for social anxiety. We will give suggestions how customization may be applied in a gradual exposure to increase the efficacy of an exposure therapy while lowering the level of difficulty for the patient.

\subsection{Explanation of the Findings}

To explain our results, we need to consider the primary manipulation of our study, i.e., avatar customization, the designed context of our study, i.e., the Shopping Task, and the larger study context, i.e., MTurk, and finally, the interaction of all three contexts.

Avatar customization has been shown to increase the effects of online inductions before [21,22], but not in the context of inducing social anxiety. Engagement with the task, explained through an increase in motivation due to social-contextual choice (customization) of the individual is one potential explanation [21]. However, another potential explanation of the increased experience of social anxiety is the heightened relevance of the task itself by feeling increased ownership over the task through having actively contributed to the design of a task element [82]. The increased motivation to engage with the task and the heightened task ownership, would suggest increased task focus, which is particularly relevant in the MTurk study context, in which participants are susceptible to distraction and attention-loss.

Our system featured the following elements that aimed to heighten participant responses to the task which likely played a role in the success of the task at eliciting fear and anxiety: Task Design. We included a number of general design considerations. First, the focus on performing in front of others, one of the commonly feared situations [51] while interacting with others. Through the repetition we ensured to distinct the experience of social anxiety from the experience of embarrassment [110]. Second, the usage of a third-person camera to display the player's avatar as a way to heighten self-awareness within the task, similar to the effects of a mirror in the physical world [63]. Audience Observers. As suggested by similar experiments [44,134], the design of the simulated audience focused on providing a negative evaluation to further highlight the socially threatening nature of the task. Prior research suggests, that the experience of social presence [55], the feeling that other individuals are within a digital interaction, plays an essential role for the experience of social anxiety in a virtual exposure. We intensified the experience of social presence through the illusion that actual observers are observing the participant through the description as well as the connection screen in the beginning of the exposure. Avatar Customization. Customization in itself is particularly effective in the context of social anxiety because customization reveals personal preferences, can be interpreted by others, and potentially results in the dreaded social rejection by others. Especially in online environments, customization is powerful because it is uncertain who really sees and evaluates our choices-e.g., is a negative response simulated or is it indeed the result of social observation and judgment, potentially even by many others [113].

Considering the distracting context of online crowd work, we show that a well-considered digital task, combined with a socially relevant manipulation of our digital representation has implications for our experience, and the potential to be foundational in designing future induction paradigms using avatar customizations. 


\subsubsection{The Explicit Influence of Customization}

As our results show, character customization affects the subjective measurements of expected and experienced fear in a web-based exposure. Consistent with prior work [10], we saw that customized avatars increased the subjective ratings of expected and experienced fear. One explanation may be the identification with their own avatar: with a customized character, it is not only their own performance, but also their own design choices for their avatar that may be evaluated by others. Prior work in digital games shows that customizing an avatar increases overall player engagement and enjoyment of the game [99]. Furthermore, customization allows players to express themselves through their avatar while hiding personal flaws [171]. But as our results show, customization may also increase the personal concern that the audience may not only judge the user's performance, the main source for experiencing social anxiety, but also the user's appearance or self-expression through the avatar.

Current models about the experience of social anxiety [70,153] offer a potential explanation. The dominant factor for the experience of social anxiety is the perception of an audience. We intensified this experience through our intervention design by representing a simulated audience (the judging characters at the other side of the counter) into the gaming context. These representations also always gave negative feedback to a highly challenging task. Through the contextualization of the game, where we mentioned that actual persons are watching the performance, the illusion of a potential audience was created. Our results show that participants with higher trait social anxiety gave higher fear ratings, which may suggest that this simulation of an evaluating audience was playing a role. As models of social anxiety suggest (see Related Work), once an audience is perceived, two major behaviours are triggered $[38,70,156]$. First, the individual scans the context for more social clues and potential social threats. These clues are used to model an image of oneself in the current context as well as the social expectations. In our experiment, the emotional indicators and the emotional response of the avatars satisfied this aspect, resulting in an elevated score of experienced as well as expected fear. Second, memories of past events are used to evaluate the current social context. Social anxiety arises from the mismatch of the expectation and the self-image of the individual $[70,161]$. Through the actual self-expression through an avatar, the individual reveals personal information about oneself. But previous work suggests that socially anxious individuals tend to avoid talking about oneself [63] and prefer anonymity in online communication [3,41,127]. However, the customized avatar may have reduced the anonymity in the context and led to an increased experience of social anxiety in comparison to predefined avatars, where no personal preferences are expressed through the avatar.

Our results suggest that an immersive web application has the potential to expose individuals to social anxiety threats, but that further studies are required to confirm and understand these effects. In our study, we show (in both conditions) that participants were responsive to the social threat, in degrees that were associated with their own trait social anxiety (see Figure 3), but that customized avatars heightened the exposure.

\subsection{Implications for Design of Exposure Therapies}

Our results provide insights into how to further enhance existing techniques for digital exposure, namely the platform, the scenario, and the self-representation:

As our results show, we were able to create an exposure through a game-related web-based interface. In comparison to existing virtual reality applications, the web application can be used without the need for expensive hardware. Our results suggest that interventions can be delivered on a computer platform and therefore allows therapists to choose a suitable solution for the needs 
of the patient. While one patient may require more immersive virtual reality solutions and an onsite training, others may not have the resources to set up immersive hardware but can access an intervention delivered online. However, in either case, exposure therapy should happen under the guidance of a mental health professional [120]. The digital accessibility of a system like ours should not automatically imply that self-guided treatment is effective. As an accessible "training exercise", exposure may be more harmful due to the lack of guidance helping patients to restructure their thoughts [64] and may in fact increase the salience of social threats.

But designers of interventions need to carefully craft the scenario and need to be aware of the representation of the participant. As our results show, the representation of the player affects the experience of social anxiety. Allowing the participant to customize the own representation may bias the experience of social anxiety. On one side, if participants customize their selfrepresentation, they may experience elevated levels of social anxiety due to additional potential threats. But our results suggest that the inverted effect could be used as well-by giving a noncustomizable avatar, the experience of social anxiety may be reduced. This can be helpful in the beginning of an exposure; guidelines for exposure therapy note that a slow increase of the level of potential social threats is a helpful strategy to balance the efficacy of the exposure with the potential risks of withdraw from the patient [35]. Using non-customized characters may allow participants to explore different, predefined roles, as prior research shows that individuals maintain self-perception and skills obtained through a digital persona even beyond the game $[19,173]$. This effect is referred as the "Proteus Effect" [173]. After gaining resilience through exploring another perspective of a scene, individuals may enable a customized avatar to map the gained insights from being another person into the "own" body.

Through the customization of the avatar, the individual may not only experience a more intense experience, but also feel more committed to the intervention. As prior work shows, customized avatars increased the user's motivation and persistence, but also performance and overall satisfaction $[65,133]$. Furthermore, the customization increased the invested effort in the shortterm [22]. These aspects may further help to tackle attrition in digital interventions.

\subsection{Ethical Considerations}

While internet and mobile based interventions may increase the accessibility of treatment, this increased access also raises several issues. As prior work suggests, cognitive behavioural therapies aim to restructure the patient's own thoughts and behaviours to increase resilience towards a feared stimulus $[8,116]$. While exposure is a powerful tool it can become overwhelming for users to successfully complete the intervention [135]. As earlier work shows, both patients and mental health professionals tend to avoid exposure therapies due to the elevated stress for the patient and the clinician. By lowering the barriers to access, one must ensure that the exposure to social threat does not become harmful for patients or clinicians. Further, earlier work suggests that the combination of exposure with cognitive restructuring techniques is a more effective approach [13]. Instead of only exposing and training patients how to behave in the feared situation, the individual reflects on the experienced situation, provoked thoughts, and their behaviours, and may practice behaviour strategies, such as avoiding using safety behaviours. Finally, previous research suggests that CBT approaches may be an effective tool, but not for every patient. Other techniques may still be helpful, such as the usage of medication may be helpful for patients which cannot bear the challenges of CBT techniques.

When implementing a digital intervention that leverages digital data, designers must always be aware of ethical considerations such as inferring identity of the user, the secure handling personal data, and the communication of very personal information with the users and how the 
intervention may affect not only the patient but also their social connections. The protection of the privacy of the patient, ensuring a safe space in which to play, and the legality of gathering data unobtrusively are also important aspects to be considered [102]. The use of data derived from digital sources is part of a growing discussion [57,83,108,112]. Prior work emphasizes the importance of the therapeutic relationship between the therapist and the patient for the success of the intervention. Therefore, designers need to make sure that the proposed solution can be only accessed within a safe space for the therapist and the patient $[78,172]$.

Overall, the use of internet-based interventions should be seen as an additional tool, which can address some shortcomings of existing solutions by lowering barriers, such as cost, distribution, and availability. But like other interventions, this approach needs to be used with the support of a therapist, who can help the individual to restructure their own thoughts and behaviour to grow resilient against social anxiety.

\subsection{Limitations and Future Research}

There are several limitations to the interpretation of our results that can be addressed by future work. First, our evaluation analyzed only the effects of one session with four trials. However, exposure techniques require repetition over multiple sessions with different stimuli $[148,170]$, and potentially personalization to individual factors that trigger social anxiety through more adaptable scenarios [120], such as giving a talk at a conference. Second, we only exposed individuals to the stimuli but did not try to restructure their own thoughts about the experienced situation. Future work may include this approach in a clinical trial, combined with restructuring exercises in a longterm study. Third, we only measured the subjective score of expected as well as experienced social anxiety. Future work may leverage the measurement of physiological data, such as heart rate or galvanic skin response (e.g., [76,87,89,107]) to gain more insights about the experience of social anxiety in the exposure as well as additional measurement tools for trait social anxiety. Fourth, the avatar customizing tool did not provide sufficient options to equally represent different people. Due to the underlying software architecture, participants chose a binary gender as a starting point; however, there were two non-binary participants in our sample. Although options could be adjusted (e.g., facial hair, breast size), the pre-defined avatars were limited in this regard. Further, the technical aspects of the system could not represent what may be felt as defining characteristics for a participant, such as curly hair or freckled skin. These technical limitations as well as the selected graphical low poly style may also explain the overall low-to-neutral scoring on the Player Identification Scale in the Predefined Avatar condition and the neutral-to-above-neutral scores in the Customized Avatar condition (See Table1 for results). Fifth, we only used one standardized questionnaire (LSAS) to assess the trait social anxiety. Although standard in clinical assessment, the LSAS is generally combined with interviews, observation, and interaction with the patient's social circle to effectively assess the presence and degree of social anxiety. Sixth, the sample: while our contribution shows that avatar customization may be more influential for individuals higher in social anxiety, future work may focus only on socially anxious individuals and explore additional aspects of customizing the avatar (e.g., the effects of experiencing anonymity with customized avatars). Seventh, the engagement with their own character: While participants in the customized avatar condition were allowed to craft their character for four minutes, participants with predefined avatars were asked to focus for 4 minutes on their selection. This may form a gap between the conditions, as participants engaged more with their character while creating a customized version in comparison to the predefined avatar selection, where players were asked to look at the selected figure instead of interacting with it. As previously explained, the missing 
interaction with the avatar may affect how players connect to their avatar, which may in turn cause the reduced experience of social anxiety within the game. Future work may use a more equally engaging approach for both conditions, to investigate the effects of engagement with their own avatar on the experience of social anxiety within games.

Through our research, future researchers may further enhance existing exposure techniques to support existing interventions. By altering and expanding on an existing technique, future researcher may tweak the representation of the surrounding environment, for example the representation of the audience, the clerk, or the environment.

\section{CONCLUSION}

Cognitive behavioral therapies (CBT) in general, and exposure therapy in particular, are effective nonpharmacological treatments for social anxiety [103]. However, digital implementations of existing exposures must stimulate the experience of an audience and the judgement of this audience, but also need to ensure that the individual with social anxiety experiences social threat. One way to foster this threat is the use of a customized avatar. In this study we explored whether the customization of avatars affects the experience of fear in a social stress task among participants with varying levels of social anxiety. Our results show that the experience of fear is mainly driven by trait social anxiety. However, we found that the effects of trait social anxiety on expected and experienced fear are stronger when using customized avatars. Further, we explored whether the customization affects how quickly participants are desensitized to the exposure over repeated iterations, suggesting that customized avatars demonstrate potential to maintain fear over multiple exposures. We provide new insights about how avatar customization affects the experience of social anxiety, which helps designers of interventions to increase the efficacy of their digital implementations of exposure therapies.

\section{ACKNOWLEDGMENTS}

We thank NSERC and SWaGUR for funding, members of the Interaction Lab for feedback, and our participants.

\section{REFERENCES}

[1] Idan M. Aderka, Stefan G. Hofmann, Angela Nickerson, Haggai Hermesh, Eva Gilboa-Schechtman, and Sofi Marom. 2012. Functional impairment in social anxiety disorder. Journal of Anxiety Disorders. https://doi.org/10.1016/j.janxdis.2012.01.003

[2] Ali M. Al-Asadi, Britt Klein, and Denny Meyer. 2014. Posttreatment attrition and its predictors, attrition bias, and treatment efficacy of the anxiety online programs. Journal of Medical Internet Research 16, 10: e232. https://doi.org/10.2196/jmir.3513

[3] Yunus Alkis, Zafer Kadirhan, and Mustafa Sat. 2017. Development and Validation of Social Anxiety Scale for Social Media Users. In Computers in Human Behavior. https://doi.org/10.1016/j.chb.2017.03.011

[4] Andrew P Allen, Paul J Kennedy, Samantha Dockray, John F Cryan, Timothy G Dinan, and Gerard Clarke. 2016. The Trier Social Stress Test: Principles and practice. Neurobiology of stress 6: 113-126. https://doi.org/10.1016/j.ynstr.2016.11.001

[5] Felwah Alqahtani and Rita Orji. 2020. Insights from user reviews to improve mental health apps. Health Informatics Journal 26, 3: 2042-2066. https://doi.org/10.1177/1460458219896492

[6] American Psychiatric Association. 2013. Diagnostic and Statistical Manual of Mental Disorders, 5th Edition (DSM-5). Diagnostic and Statistical Manual of Mental Disorders 4th edition TR.: 280 https://doi.org/10.1176/appi.books.9780890425596.744053

[7] Julio Arboleda-Flórez and Heather Stuart. 2012. From Sin to Science: Fighting the Stigmatization of Mental Illnesses. The Canadian Journal of Psychiatry 57, 8: 457-463. https://doi.org/10.1177/070674371205700803 
[8] Joanna J. Arch and Michelle G. Craske. 2009. First-line Treatment: A Critical Appraisal of Cognitive Behavioral Therapy Developments and Alternatives. Psychiatric Clinics of North America. https://doi.org/10.1016/j.psc.2009.05.001

[9] Laura Aymerich-Franch and J Bailenson. 2014. The use of doppelgangers in virtual reality to treat public speaking anxiety: a gender comparison. In Proceedings of the International Society for Presence Research Annual Conference, $173-186$.

[10] Laura Aymerich-Franch, RenÃ@ F. Kizilcec, and Jeremy N. Bailenson. 2014. The Relationship between Virtual Self Similarity and Social Anxiety. Frontiers in Human Neuroscience. https://doi.org/10.3389/fnhum.2014.00944

[11] Christine Bailey and Michael Katchabaw. 2008. An emergent framework for realistic psychosocial behaviour in non player characters. In Proceedings of the 2008 Conference on Future Play: Research, Play, Share, 17-24.

[12] Sandra L. Baker, Nina Heinrichs, Hyo Jin Kim, and Stefan G. Hofmann. 2002. The Liebowitz social anxiety scale as a self-report instrument: A preliminary psychometric analysis. Behaviour Research and Therapy. https://doi.org/10.1016/S0005-7967(01)00060-2

[13] Borwin Bandelow, Markus Reitt, Christian Röver, Sophie Michaelis, Yvonne Görlich, and Dirk Wedekind. 2015. Efficacy of treatments for anxiety disorders: A meta-analysis. International Clinical Psychopharmacology 30, 4: 183192. https://doi.org/10.1097/YIC.0000000000000078

[14] Tyson V. Barker, Sonya Troller-Renfree, Daniel S. Pine, and Nathan A. Fox. 2015. Individual differences in social anxiety affect the salience of errors in social contexts. Cognitive, Affective and Behavioral Neuroscience 15, 4: 723735. https://doi.org/10.3758/s13415-015-0360-9

[15] H. Baumeister, L. Nowoczin, J. Lin, H. Seifferth, J. Seufert, K. Laubner, and D. D. Ebert. 2014. Impact of an acceptance facilitating intervention on diabetes patients' acceptance of Internet-based interventions for depression: A randomized controlled trial. Diabetes Research and Clinical Practice 105, 1: 30-39. https://doi.org/10.1016/j.diabres.2014.04.031

[16] Gary Bente, Sabine Rüggenberg, Nicole C Krämer, and Felix Eschenburg. 2008. Avatar-mediated networking: Increasing social presence and interpersonal trust in net-based collaborations. Human communication research 34,2 : 287-318.

[17] Anke Berns, Antonio Gonzalez-Pardo, and David Camacho. 2013. Game-like language learning in 3-D virtual environments. Computers \& Education 60, 1:210-220.

[18] Katherine Bessière, A. Fleming Seay, and Sara Kiesler. 2007. The ideal elf: Identity exploration in world of warcraft. Cyberpsychology and Behavior. https://doi.org/10.1089/cpb.2007.9994

[19] Yulong Bian, Chao Zhou, Yu Tian, Peng Wang, and Fengqiang Gao. 2015. The Proteus Effect: Influence of Avatar Appearance on Social Interaction in Virtual Environments BT - HCI International 2015 - Posters' Extended Abstracts. $78-83$.

[20] Max V. Birk, Cheralyn Atkins, Jason T. Bowey, and Regan L. Mandryk. 2016. Fostering intrinsic motivation through avatar identification in digital games. In Conference on Human Factors in Computing Systems - Proceedings. https://doi.org/10.1145/2858036.2858062

[21] Max V. Birk and Regan L. Mandryk. 2018. Combating attrition in digital self-improvement programs using avatar customization. In Conference on Human Factors in Computing Systems - Proceedings. https://doi.org/10.1145/3173574.3174234

[22] Max Valentin Birk and Regan Lee Mandryk. 2019. Improving the efficacy of cognitive training for digital mental health interventions through avatar customization: Crowdsourced quasi-experimental study. Journal of Medical Internet Research. https://doi.org/10.2196/10133

[23] Anke W. Blöte, Anne C. Miers, David A. Heyne, David M. Clark, and P. Michiel Westenberg. 2014. The relation between social anxiety and audience perception: Examining clark and wells' (1995) model among adolescents. Behavioural and Cognitive Psychotherapy. https://doi.org/10.1017/S1352465813000271

[24] C. Botella, J. Breton-López, S. Quero, R. M. Baños, A. García-Palacios, I. Zaragoza, and M. Alcaniz. 2011. Treating cockroach phobia using a serious game on a mobile phone and augmented reality exposure: A single case study. Computers in Human Behavior 27, 1: 217-227. https://doi.org/10.1016/j.chb.2010.07.043

[25] Cristina Botella, A. Gracía-Palacios, H. Villa, R. M. Baños, S. Quero, M. Alcañiz, and G. Riva. 2007. Virtual reality exposure in the treatment of panic disorder and agoraphobia: A controlled study. Clinical Psychology and Psychotherapy. https://doi.org/10.1002/cpp.524

[26] Stéphane Bouchard, Sophie Côté, Julie St-Jacques, Geneviève Robillard, and Patrice Renaud. 2006. Effectiveness of virtual reality exposure in the treatment of arachnophobia using 3D games. Technology and health care: official journal of the European Society for Engineering and Medicine 14, 1: 19-27.

[27] N D Bowman, J Wasserman, and J Banks. 2018. Development of the video game demand scale. Video games: A medium that demands our attention: 208-233. 
[28] Willem-paul Brinkman. 2008. Virtual Reality Exposure Therapy for Social Phobia: A Pilot Study in Evoking Fear in a Virtual World. HCI for Technology Enhanced Learning. Liverpool, UK.: 83-95.

[29] Faith Brozovich and Richard G Heimberg. 2011. The Relationship of Post-Event Processing to Self-Evaluation of Performance in Social Anxiety. Behavior Therapy 42, 2: $224-235$. https://doi.org/https://doi.org/10.1016/j.beth.2010.08.005

[30] Lia Bryant, Bridget Garnham, Deirdre Tedmanson, and Sophie Diamandi. 2015. Tele-social work and mental health in rural and remote communities in Australia. International Social Work 61, 1: 143-155. https://doi.org/10.1177/0020872815606794

[31] Dennis Buede, Bradley DeBlois, Doug Maxwell, and Beverly McCarter. 2013. Filling the need for intelligent, adaptive non-player characters. In Proceedings of the Interservice/Industry Training, Simulation, and Education Conference (I/ITSEC).

[32] Grigore C Burdea. 2003. Virtual rehabilitation-benefits and challenges. Methods of information in medicine 42, 05: 519-523.

[33] Vicente E Caballo, Isabel C Salazar, Víctor Arias, Stefan G Hofmann, and Joshua Curtiss. 2019. Psychometric properties of the Liebowitz Social Anxiety Scale in a large cross-cultural Spanish and Portuguese speaking sample. Revista brasileira de psiquiatria (Sao Paulo, Brazil : 1999) 41, 2: 122-130. https://doi.org/10.1590/1516-4446-20180006

[34] Emily Carl, Aliza T. Stein, Andrew Levihn-Coon, Jamie R. Pogue, Barbara Rothbaum, Paul Emmelkamp, Gordon J.G. Asmundson, Per Carlbring, and Mark B. Powers. 2019. Virtual reality exposure therapy for anxiety and related disorders: A meta-analysis of randomized controlled trials. Journal of Anxiety Disorders. https://doi.org/10.1016/j.janxdis.2018.08.003

[35] Rachel K. Chesham, John M. Malouff, and Nicola S. Schutte. 2018. Meta-Analysis of the Efficacy of Virtual Reality Exposure Therapy for Social Anxiety. Behaviour Change. https://doi.org/10.1017/bec.2018.15

[36] Arnaud Chevalier, Steve Gibbons, Andy Thorpe, Martin Snell, and Sherria Hoskins. 2009. Students' academic selfperception. Economics of Education Review 28, 6: 716-727.

[37] D. a. Clark and Adrian Wells. 1995. A cognitive model of social phobia. Social phobia: Diagnosis, assessment, and Treatment.

[38] David M Clark, W R Crozier, and L E Alden. 2005. A cognitive perspective on social phobia. The essential handbook of social anxiety for clinicians: 193-218.

[39] Vítor Alexandre Coelho and Ana Maria Romão. 2018. The relation between social anxiety, social withdrawal and (cyber)bullying roles: A multilevel analysis. Computers in Human Behavior. https://doi.org/10.1016/j.chb.2018.04.048

[40] Tom Cole, Paul Cairns, and Marco Gillies. 2015. Emotional and Functional Challenge in Core and Avant-Garde Games. In Proceedings of the 2015 Annual Symposium on Computer-Human Interaction in Play (CHI PLAY '15), 121-126. https://doi.org/10.1145/2793107.2793147

[41] Samantha Cuming and Ronald M. Rapee. 2010. Social anxiety and self-protective communication style in close relationships. Behaviour Research and Therapy. https://doi.org/10.1016/j.brat.2009.09.010

[42] Judith Dams, Hans Helmut König, Florian Bleibler, Jürgen Hoyer, Jörg Wiltink, Manfred E. Beutel, Simone Salzer, Stephan Herpertz, Ulrike Willutzki, Bernhard Strauß, Eric Leibing, Falk Leichsenring, and Alexander Konnopka. 2017. Excess costs of social anxiety disorder in Germany. Journal of Affective Disorders. https://doi.org/10.1016/j.jad.2017.01.041

[43] Dan Chisholm Dan Chisholm. 2013. Investing in mental health: evidence for action.

[44] M. Dechant, S. Trimpl, C. Wolff, A. Mühlberger, and Y. Shiban. 2017. Potential of virtual reality as a diagnostic tool for social anxiety: A pilot study. Computers in Human Behavior 76. https://doi.org/10.1016/j.chb.2017.07.005

[45] Martin Dechant, Susanne Poeller, Colby Johanson, Katelyn Wiley, and Regan L. Mandryk. 2020. In-game and Out-ofgame Social Anxiety Influences Player Motivations, Activities, and Experiences in MMORPGs. https://doi.org/10.1145/3313831.3376734

[46] Julia Diemer, Georg W. Alpers, Henrik M. Peperkorn, Youssef Shiban, Andreas MÃ̄//4hlberger, and Andreas Mühlberger. 2015. The impact of perception and presence on emotional reactions: a review of research in virtual reality. Frontiers in Psychology 6, January: 1-9. https://doi.org/10.3389/fpsyg.2015.00026

[47] Julia Diemer, Nora Lohkamp, Andreas Mühlberger, and Peter Zwanzger. 2016. Fear and physiological arousal during a virtual height challenge-effects in patients with acrophobia and healthy controls. Journal of Anxiety Disorders. https://doi.org/10.1016/j.janxdis.2015.10.007

[48] LORAH D DORN, JOHN C CAMPO, SATHJA THATO, RONALD E DAHL, DANIEL LEWIN, RAMAMURTI CHANDRA, and CARLO DI LORENZO. 2003. Psychological Comorbidity and Stress Reactivity in Children and Adolescents With Recurrent Abdominal Pain and Anxiety Disorders. Journal of the American Academy of Child \& Adolescent Psychiatry 42, 1: 66-75. https://doi.org/https://doi.org/10.1097/00004583-200301000-00012 
[49] Robert L. DuPont, Dorothy P. Rice, Leonard S. Miller, Sarah S. Shiraki, Clayton R. Rowland, and Henrick J. Harwood. 1996. Economic costs of anxiety disorders. Anxiety. https://doi.org/10.1002/(SICI)1522-7154(1996)2:4<167::AIDANXI2>3.0.CO;2-L

[50] David D Ebert, Tom Van Daele, Tine Nordgreen, Maria Karekla, Angelo Compare, Cristina Zarbo, Agostino Brugnera, Svein Øverland, Glauco Trebbi, and Kit L Jensen. 2018. Internet-and mobile-based psychological interventions: applications, efficacy, and potential for improving mental health. European Psychologist.

[51] Renée El-Gabalawy, Brian Cox, Ian Clara, and Corey Mackenzie. 2010. Assessing the validity of social anxiety disorder subtypes using a nationally representative sample. Journal of Anxiety Disorders. https://doi.org/10.1016/j.janxdis.2009.11.003

[52] Gunther Eysenbach. 2005. The law of attrition. Journal of Medical Internet Research 7 , e11. https://doi.org/10.2196/jmir.7.1.e11

[53] Lydia Fehm, Katja Beesdo, Frank Jacobi, and Agnes Fiedler. 2008. Social anxiety disorder above and below the diagnostic threshold: Prevalence, comorbidity and impairment in the general population. Social Psychiatry and Psychiatric Epidemiology. https://doi.org/10.1007/s00127-007-0299-4

[54] Lydia Fehm, Antoine Pelissolo, Tomas Furmark, and Hans Ulrich Wittchen. 2005. Size and burden of social phobia in Europe. European Neuropsychopharmacology. https://doi.org/10.1016/j.euroneuro.2005.04.002

[55] Anna Felnhofer, Helmut Hlavacs, Leon Beutl, Ilse Kryspin-Exner, and Oswald D. Kothgassner. 2019. Physical Presence, Social Presence, and Anxiety in Participants with Social Anxiety Disorder During Virtual Cue Exposure. Cyberpsychology, Behavior, and Social Networking 22, 1: 46-50. https://doi.org/10.1089/cyber.2018.0221

[56] Ulrike Feske and Dianne L. Chambless. 1995. Cognitive behavioral versus exposure only treatment for social phobia: A meta-analysis. Behavior Therapy. https://doi.org/10.1016/S0005-7894(05)80040-1

[57] Luciano Floridi and Mariarosaria Taddeo. 2016. What is data ethics? Philosophical Transactions of the Royal Society A: Mathematical, Physical and Engineering Sciences. https://doi.org/10.1098/rsta.2016.0360

[58] Edna B. Foa and Michael J. Kozak. 1986. Emotional Processing of Fear. Exposure to Corrective Information. Psychological Bulletin. https://doi.org/10.1037/0033-2909.99.1.20

[59] Alana E Foley, Julianne B Herts, Francesca Borgonovi, Sonia Guerriero, Susan C Levine, and Sian L Beilock. 2017. The math anxiety-performance link: A global phenomenon. Current Directions in Psychological Science 26, 1: 52-58.

[60] T. Furmark. 2002. Social phobia: Overview of community surveys. Acta Psychiatrica Scandinavica. https://doi.org/10.1034/j.1600-0447.2002.1r103.x

[61] Daniel L Gardner and Theresa Jean Tanenbaum. 2018. Dynamic Demographics: Lessons from a Large-Scale Census of Performative Possibilities in Games. In Proceedings of the 2018 CHI Conference on Human Factors in Computing Systems (CHI '18), 1-12. https://doi.org/10.1145/3173574.3173667

[62] Alison Gazzard. 2009. The avatar and the player: understanding the relationship beyond the screen. In 2009 Conference in games and virtual worlds for serious applications, 190-193.

[63] Lindsay George and Lusia Stopa. 2008. Private and public self-awareness in social anxiety. Journal of Behavior Therapy and Experimental Psychiatry. https://doi.org/10.1016/j.jbtep.2006.09.004

[64] Dina Gordon, Judy Wong, and Richard G. Heimberg. 2014. Cognitive-Behavioral Therapy for Social Anxiety Disorder: The State of the Science. In The Wiley Blackwell Handbook of Social Anxiety Disorder. John Wiley \& Sons, Ltd, 475-497. https://doi.org/10.1002/9781118653920.ch22

[65] Jérôme Guegan, Stéphanie Buisine, Fabrice Mantelet, Nicolas Maranzana, and Frédéric Segonds. 2016. Avatarmediated creativity: When embodying inventors makes engineers more creative. Computers in Human Behavior 61: $165-175$

[66] Katherina K. Hauner, Susan Mineka, Joel L. Voss, and Ken A. Paller. 2012. Exposure therapy triggers lasting reorganization of neural fear processing. Proceedings of the National Academy of Sciences of the United States of America 109, 23: 9203-9208. https://doi.org/10.1073/pnas.1205242109

[67] David Hauser, Gabriele Paolacci, and Jesse Chandler. 2019. Common concerns with mturk as a participant pool: Evidence and solutions. In Handbook of Research Methods in Consumer Psychology. https://doi.org/10.4324/9781351137713

[68] Dorothée Hefner, Christoph Klimmt, and Peter Vorderer. 2007. Identification with the Player Character as Determinant of Video Game Enjoyment BT - Entertainment Computing - ICEC 2007. 39-48.

[69] Richard G. Heimberg. 2002. Cognitive-behavioral therapy for social anxiety disorder: Current status and future directions. Biological Psychiatry. https://doi.org/10.1016/S0006-3223(01)01183-0

[70] Richard G. Heimberg, Faith A. Brozovich, and Ronald M. Rapee. 2010. A Cognitive Behavioral Model of Social Anxiety Disorder: Update and Extension. In Social Anxiety. https://doi.org/10.1016/B978-0-12-375096-9.00015-8 
[71] Nina Heinrichs and Stefan G. Hofmann. 2001. Information processing in social phobia: A critical review. Clinical Psychology Review. https://doi.org/10.1016/S0272-7358(00)00067-2

[72] Colette Hirsch, Tim Meynen, and David Clark. 2004. Negative self-imagery in social anxiety contaminates social interactions. Memory 12, 4: 496-506. https://doi.org/10.1080/09658210444000106

[73] Colette R. Hirsch, David M. Clark, Andrew Mathews, and Ruth Williams. 2003. Self-images play a causal role in social phobia. Behaviour Research and Therapy. https://doi.org/10.1016/S0005-7967(02)00103-1

[74] Eric Horvitz, Andy Jacobs, and David Hovel. Attention-Sensitive Alerting. https://doi.org/10.5555/2073796.207383

[75] Zaheer Hussain and Mark D. Griffiths. 2008. Gender swapping and socializing in cyberspace: An exploratory study. Cyberpsychology and Behavior. https://doi.org/10.1089/cpb.2007.0020

[76] Nicholas C. Jacobson, Berta Summers, and Sabine Wilhelm. 2020. Digital biomarkers of social anxiety severity: Digital phenotyping using passive smartphone sensors. Journal of Medical Internet Research. https://doi.org/10.2196/16875

[77] Philip Jefferies and Michael Ungar. 2020. Social anxiety in young people: A prevalence study in seven countries. PLOS ONE 15, 9: 1-18. https://doi.org/10.1371/journal.pone.0239133

[78] Martin Johannes Dechant, Julian Frommel, and Regan Mandryk. 2021. Assessing Social Anxiety Through Digital Biomarkers Embedded in a Gaming Task. In Proceedings of the 2021 CHI Conference on Human Factors in Computing Systems (CHI '21). https://doi.org/10.1145/3411764.3445238

[79] Colby Johanson. 2020. colbyj/bride-of-frankensystem 1.1. https://doi.org/10.5281/ZENODO.3738761

[80] Colby Johanson, Carl Gutwin, Jason T. Bowey, and Regan L. Mandryk. 2019. Press pause when you play: Comparing spaced practice intervals for skill development in games. In CHI PLAY 2019 - Proceedings of the Annual Symposium on Computer-Human Interaction in Play. https://doi.org/10.1145/3311350.3347195

[81] Fanny Kählke, Thomas Berger, Ava Schulz, Harald Baumeister, Matthias Berking, Randy P. Auerbach, Ronny Bruffaerts, Pim Cuijpers, Ronald C. Kessler, and David Daniel Ebert. 2019. Efficacy of an unguided internet-based self-help intervention for social anxiety disorder in university students: A randomized controlled trial. International Journal of Methods in Psychiatric Research 28, 2: e1766. https://doi.org/10.1002/mpr.1766

[82] Ulrike Kaiser, Martin Schreier, and Chris Janiszewski. 2017. The self-expressive customization of a product can improve performance. Journal of Marketing Research. https://doi.org/10.1509/jmr.14.0293

[83] B Kenwright. 2018. Virtual Reality: Ethical Challenges and Dangers [Opinion]. IEEE Technology and Society Magazine 37, 4: 20-25. https://doi.org/10.1109/MTS.2018.2876104

[84] Martin Kocur, Philipp Schauhuber, Valentin Schwind, Christian Wolff, and Niels Henze. 2020. The Effects of Self-and External Perception of Avatars on Cognitive Task Performance in Virtual Reality. In 26th ACM Symposium on Virtual Reality Software and Technology, 1-11.

[85] A. Kodal, I. Bjelland, R. Gjestad, G. J. Wergeland, O. E. Havik, E. R. Heiervang, and K. Fjermestad. 2017. Subtyping social anxiety in youth. Journal of Anxiety Disorders. https://doi.org/10.1016/j.janxdis.2017.03.009

[86] Rachel Kowert, Jens Vogelgesang, Ruth Festl, and Thorsten Quandt. 2015. Psychosocial causes and consequences of online video game play. Computers in Human Behavior. https://doi.org/10.1016/j.chb.2014.11.074

[87] Mariska E. Kret, Jeroen J. Stekelenburg, Beatrice de Gelder, and Karin Roelofs. 2017. From face to hand: Attentional bias towards expressive hands in social anxiety. Biological Psychology. https://doi.org/10.1016/j.biopsycho.2015.11.016

[88] Anil Kumar and H R Phookun. 2016. Barriers in the treatment of psychiatric disorders. Open Journal of Psychiatry \& Allied Sciences 7, 2: 99-102.

[89] M. H. Lader. 1967. Palmar skin conductance measures in anxiety and phobic states. Journal of Psychosomatic Research. https://doi.org/10.1016/0022-3999(67)90021-9

[90] Petri Lankoski and Staffan Björk. 2007. Gameplay Design Patterns for Believable Non-Player Characters. In DiGRA Conference, 416-423.

[91] Y. Lecrubier, H. U. Wittchen, C. Faravelli, J. Bobes, A. Patel, and M. Knapp. 2000. A European perspective on social anxiety disorder. European Psychiatry. https://doi.org/10.1016/S0924-9338(00)00216-9

[92] Falk Leichsenring, Simone Salzer, Manfred E. Beutel, Stephan Herpertz, Wolfgang Hiller, Juergen Hoyer, Johannes Huesing, Peter Joraschky, Bjoern Nolting, Karin Poehlmann, Viktoria Ritter, Ulrich Stangier, Bernhard Strauss, Susan Tefikow, Tobias Teismann, Ulrike Willutzki, Joerg Wiltink, and Eric Leibing. 2014. Long-term outcome of psychodynamic therapy and cognitive-behavioral therapy in social anxiety disorder. American Journal of Psychiatry 171, 10: 1074-1082. https://doi.org/10.1176/appi.ajp.2014.13111514

[93] Alex Lenk. 2020. Advanced People Pack 2. Retrieved from https://assetstore.unity.com/packages/3d/characters/humanoids/humans/advanced-people-pack-2-170756

[94] Michael Lewis. 1995. Embarrassment: The emotion of self-exposure and evaluation.

PACM on Human-Computer Interaction, Vol. 5, No. CHI PLAY, Article 248, Publication date: September 2021. 
[95] Dong Dong Li, Albert Kien Liau, and Angeline Khoo. 2013. Player-Avatar Identification in video gaming: Concept and measurement. Computers in Human Behavior 29, 1: 257-263.

[96] M. R. Liebowitz. 1987. Liebowitz Social Anxiety Scale. Modern Problems of Pharmapsychiatry.

[97] Silja Litvin, Rob Saunders, Markus A. Maier, and Stefan Lüttke. 2020. Gamification as an approach to improve resilience and reduce attrition in mobile mental health interventions: A randomized controlled trial. PLOS ONE 15, 9: e0237220. https://doi.org/10.1371/journal.pone.0237220

[98] Ian J. Livingston, Carl Gutwin, Regan L. Mandryk, and Max Birk. 2014. How Players value their characters in world of warcraft. In Proceedings of the ACM Conference on Computer Supported Cooperative Work, CSCW. https://doi.org/10.1145/2531602.2531661

[99] Jan Van Looy, Cédric Courtois, Melanie De Vocht, and Lieven De Marez. 2012. Player Identification in Online Games: Validation of a Scale for Measuring Identification in MMOGs. Media Psychology. https://doi.org/10.1080/15213269.2012.674917

[100] Regan L. Mandryk, Max V. Birk, Adam Lobel, Marieke van Rooij, Isabela Granic, and Vero Vanden Abeele. 2017. Games for the Assessment and Treatment of Mental Health. https://doi.org/10.1145/3130859.3131445

[101] Regan L Mandryk and M Stella Atkins. 2007. A fuzzy physiological approach for continuously modeling emotion during interaction with play technologies. International journal of human-computer studies 65, 4: 329-347.

[102] Regan Lee Mandryk and Max Valentin Birk. 2019. The potential of game-based digital biomarkers for modeling mental health. Journal of Medical Internet Research. https://doi.org/10.2196/13485

[103] Evan Mayo-Wilson, Sofia Dias, Ifigeneia Mavranezouli, Kayleigh Kew, David M. Clark, A. E. Ades, and Stephen Pilling. 2014. Psychological and pharmacological interventions for social anxiety disorder in adults: A systematic review and network meta-analysis. The Lancet Psychiatry. https://doi.org/10.1016/S2215-0366(14)70329-3

[104] Victoria McArthur and Jennifer Jenson. 2014. E is for Everyone? Best Practices for the Socially Inclusive Design of Avatar Creation Interfaces. In Proceedings of the 2014 Conference on Interactive Entertainment (IE2014), 1-8. https://doi.org/10.1145/2677758.2677783

[105] Victoria McArthur, Robert John Teather, and Jennifer Jenson. 2015. The Avatar Affordances Framework: Mapping Affordances and Design Trends in Character Creation Interfaces. In Proceedings of the 2015 Annual Symposium on Computer-Human Interaction in Play (CHI PLAY '15), 231-240. https://doi.org/10.1145/2793107.2793121

[106] Richard J. McNally. 2007. Mechanisms of exposure therapy: How neuroscience can improve psychological treatments for anxiety disorders. Clinical Psychology Review. https://doi.org/10.1016/j.cpr.2007.01.003

[107] Lisa M. McTeague, Peter J. Lang, Marie Claude Laplante, Bruce N. Cuthbert, Cyd C. Strauss, and Margaret M. Bradley. 2009. Fearful Imagery in Social Phobia: Generalization, Comorbidity, and Physiological Reactivity. Biological Psychiatry 65, 5: 374-382. https://doi.org/10.1016/j.biopsych.2008.09.023

[108] Jacob Metcalf and Kate Crawford. 2016. Where are human subjects in Big Data research? The emerging ethics divide. Big Data and Society. https://doi.org/10.1177/2053951716650211

[109] A. C. Miers, A. W. Blöte, M. De Rooij, C. L. Bokhorst, and P. M. Westenberg. 2013. Trajectories of social anxiety during adolescence and relations with cognition, social competence, and temperament. Journal of Abnormal Child Psychology. https://doi.org/10.1007/s10802-012-9651-6

[110] Rowland S Miller. 2014. Embarrassment and Social Anxiety Disorder: Fraternal Twins or Distant Cousins? In Social Anxiety, Stefan G Hofmann and Patricia M B T - Social Anxiety (Third Edition) DiBartolo (eds.). Elsevier, San Diego, 117-140. https://doi.org/10.1016/B978-0-12-394427-6.00005-4

[111] Alexander Miloff, Arvid Marklund, and Per Carlbring. 2015. The challenger app for social anxiety disorder: New advances in mobile psychological treatment. Internet Interventions 2, 382-391. https://doi.org/10.1016/j.invent.2015.08.001

[112] Brent Daniel Mittelstadt, Patrick Allo, Mariarosaria Taddeo, Sandra Wachter, and Luciano Floridi. 2016. The ethics of algorithms: Mapping the debate. Big Data \& Society 3, 2: 2053951716679679.

[113] Victoria A. Mountford, Kate Tchanturia, and Lucia Valmaggia. 2016. "What Are You Thinking When You Look at Me?" A Pilot Study of the Use of Virtual Reality in Body Image. Cyberpsychology, Behavior, and Social Networking. https://doi.org/10.1089/cyber.2015.0169

[114] National Clinical Guideline National Collaborating Centre for Mental Health. 2013. Social Anxiety Disorder. Recognition. Assessment and Treatment. New England Journal of Medicine. https://doi.org/10.1056/NEJMcp1614701

[115] Maurice M. Ohayon and Alan F. Schatzberg. 2010. Social phobia and depression: Prevalence and comorbidity. Journal of Psychosomatic Research. https://doi.org/10.1016/j.jpsychores.2009.07.018

[116] Christian Otte. 2011. Cognitive behavioral therapy in anxiety disorders: Current state of the evidence. Dialogues in Clinical Neuroscience. 
[117] Cale J. Passmore and Regan L. Mandryk. 2018. An about face: Diverse self-representation in games. In CHI PLAY 2018 - Proceedings of the 2018 Annual Symposium on Computer-Human Interaction in Play. https://doi.org/10.1145/3270316.3271552

[118] Cale J Passmore, Max V Birk, and Regan L Mandryk. 2018. The privilege of immersion: Racial and ethnic experiences, perceptions, and beliefs in digital gaming. In Proceedings of the $2018 \mathrm{CHI}$ Conference on Human Factors in Computing Systems, 1-19.

[119] Cale J Passmore, Mathew K Miller, Jun Liu, Cody J Phillips, and Regan L Mandryk. 2020. A Cheating Mood: The Emotional and Psychological Benefits of Cheating in Single-Player Games. In Proceedings of the Annual Symposium on Computer-Human Interaction in Play, 58-70.

[120] Antoine Pelissolo, Sandra Abou Kassm, and Lauriane Delhay. 2019. Therapeutic strategies for social anxiety disorder: where are we now? Expert Review of Neurotherapeutics 19, 12: 1179-1189. https://doi.org/10.1080/14737175.2019.1666713

[121] D Pertaub, M Slater, and C Barker. 2002. An Experiment on Public Speaking Anxiety in Response to Three Different Types of Virtual Audience. Presence 11, 1: 68-78. https://doi.org/10.1162/105474602317343668

[122] Daniel Pimentel and Sri Kalyanaraman. 2020. Customizing Your Demons: Anxiety Reduction via Anthropomorphizing and Destroying an "Anxiety Avatar." Frontiers in Psychology 11.

[123] Daniel S. Pine, Patricia Cohen, Diana Gurley, Judith Brook, and Yuju Ma. 1998. The risk for early-adulthood anxiety and depressive disorders in adolescents with anxiety and depressive disorders. Archives of General Psychiatry. https://doi.org/10.1001/archpsyc.55.1.56

[124] Kristie L. Poole, Ryan J. Van Lieshout, and Louis A. Schmidt. 2017. Exploring relations between shyness and social anxiety disorder: The role of sociability. Personality and Individual Differences. https://doi.org/10.1016/j.paid.2017.01.020

[125] Mark B. Powers, Nicole F. Briceno, Robert Gresham, Ernest N. Jouriles, Paul M.G. Emmelkamp, and Jasper A.J. Smits. 2013. Do conversations with virtual avatars increase feelings of social anxiety? Journal of Anxiety Disorders. https://doi.org/10.1016/j.janxdis.2013.03.003

[126] Gianfranco Preciado Cossio and Giacomo Preciado Cossio. 2012. Use of Virtual Reality Systems and Augmented Reality for Visualizing Acrophobic Environments. In WORLD CONGRESS ON ENGINEERING AND COMPUTER SCIENCE, WCECS 2012, VOL I.

[127] Shiri Prizant-Passal, Tomer Shechner, and Idan M Aderka. 2016. Social anxiety and internet use - A meta-analysis: What do we know? What are we missing? Computers in Human Behavior 62: 221-229. https://doi.org/https://doi.org/10.1016/j.chb.2016.04.003

[128] S Rachman and Steven Taylor. 1993. Analyses of claustrophobia. Journal of Anxiety disorders.

[129] Beatrice Rammstedt and Oliver P. John. 2007. Measuring personality in one minute or less: A 10-item short version of the Big Five Inventory in English and German. Journal of Research in Personality. https://doi.org/10.1016/j.jrp.2006.02.001

[130] Ronald M. Rapee and Maree J. Abbott. 2007. Modelling relationships between cognitive variables during and following public speaking in participants with social phobia. Behaviour Research and Therapy. https://doi.org/10.1016/j.brat.2007.08.008

[131] Ronald M. Rapee and Susan H. Spence. 2004. The etiology of social phobia: Empirical evidence and an initial model. Clinical Psychology Review. https://doi.org/10.1016/j.cpr.2004.06.004

[132] Rabindra Ratan, David Beyea, Benjamin J Li, and Luis Graciano. 2020. Avatar characteristics induce users' behavioral conformity with small-to-medium effect sizes: A meta-analysis of the proteus effect. Media Psychology 23, 5: 651675 .

[133] Rabindra Ratan, R V Rikard, Celina Wanek, Madison McKinley, Lee Johnson, and Young June Sah. 2016. Introducing Avatarification: An experimental examination of how avatars influence student motivation. In 2016 49th Hawaii International Conference on System Sciences (HICSS), 51-59.

[134] Jonas Reichenberger, Sonja Porsch, Jasmin Wittmann, Verena Zimmermann, and Youssef Shiban. 2017. Social fear conditioning paradigm in virtual reality: Social vs. electrical aversive conditioning. Frontiers in Psychology. https://doi.org/10.3389/fpsyg.2017.01979

[135] David C.S. Richard and Andrew T. Gloster. 2007. Exposure therapy has a public relations problem: A dearth of litigation amid a wealth of concern. In Handbook of Exposure Therapies. https://doi.org/10.1016/B978-0125874212/50019-3

[136] David C S Richard, Dean Lauterbach, and Andrew T Gloster. 2007. Chapter 1 - Description, mechanisms of action, and assessment. In David C S Richard and Dean B T - Handbook of Exposure Therapies Lauterbach (eds.). Academic Press, Burlington, 1-28. https://doi.org/https://doi.org/10.1016/B978-012587421-2/50002-8 
[137] Thomas L. Rodebaugh, Robert M. Holaway, and Richard G. Heimberg. 2004. The treatment of social anxiety disorder. Clinical Psychology Review. https://doi.org/10.1016/j.cpr.2004.07.007

[138] Denise Rousseau. 1995. Psychological Contracts in Organizations: Understanding Written and Unwritten Agreements. SAGE Publications, Inc., 2455 Teller Road, Thousand Oaks California 91320 United States . https://doi.org/10.4135/9781452231594

[139] A. M. Ruscio, T. A. Brown, W. T. Chiu, J. Sareen, M. B. Stein, and R. C. Kessler. 2008. Social fears and social phobia in the USA: Results from the National Comorbidity Survey Replication. Psychological Medicine. https://doi.org/10.1017/S0033291707001699

[140] Graham Russell and Steve Shaw. 2009. A study to investigate the prevalence of social anxiety in a sample of higher education students in the United Kingdom. Journal of Mental Health 18, 3: 198-206. https://doi.org/10.1080/09638230802522494

[141] Richard M. Ryan and Edward L. Deci. 2000. Self-determination theory and the facilitation of intrinsic motivation, social development, and well-being. American Psychologist. https://doi.org/10.1037/0003-066X.55.1.68

[142] Richard M. Ryan, C. Scott Rigby, and Andrew Przybylski. 2006. The motivational pull of video games: A selfdetermination theory approach. Motivation and Emotion. https://doi.org/10.1007/s11031-006-9051-8

[143] Nina K. Rytwinski, David M. Fresco, Richard G. Heimberg, Meredith E. Coles, Michael R. Liebowitz, Shadha Cissell, Murray B. Stein, and Stefan G. Hofmann. 2009. Screening for social anxiety disorder with the self-report version of the liebowitz social anxiety scale. Depression and Anxiety. https://doi.org/10.1002/da.20503

[144] Eduardo Sabaté. 2015. Adherence to long-term therapies: Evidence for Action. WHO ACTION. Retrieved February 11, 2021 from http://www.who.int/chp/knowledge/publications/adherence_report/en/

[145] Franziska Schreiber, Volkmar Höfling, Ulrich Stangier, Christiane Bohn, and Regina Steil. 2012. A cognitive model of social phobia: Applicability in a large adolescent sample. International Journal of Cognitive Therapy. https://doi.org/10.1521/ijct.2012.5.3.341

[146] Ulrike Schultze. 2011. The avatar as sociomaterial entanglement: a performative perspective on identity, agency and world-making in virtual worlds.

[147] Abdullah Shehab and Abdishakur Abdulle. 2011. Cognitive and autonomic dysfunction measures in normal controls, white coat and borderline hypertension. BMC Cardiovascular Disorders. https://doi.org/10.1186/1471-2261-11-3

[148] Youssef Shiban, Paul Pauli, and Andreas Mühlberger. 2013. Effect of multiple context exposure on renewal in spider phobia. Behaviour Research and Therapy. https://doi.org/10.1016/j.brat.2012.10.007

[149] Youssef Shiban, Henrik Peperkorn, Georg W. Alpers, Paul Pauli, and Andreas Mühlberger. 2016. Influence of perceptual cues and conceptual information on the activation and reduction of claustrophobic fear. Journal of Behavior Therapy and Experimental Psychiatry. https://doi.org/10.1016/j.jbtep.2015.11.002

[150] Rebecca S. Siegel, Annette M. la Greca, and Hannah M. Harrison. 2009. Peer victimization and social anxiety in adolescents: Prospective and reciprocal relationships. Journal of Youth and Adolescence. https://doi.org/10.1007/s10964-009-9392-1

[151] Mel Slater, David-Paul Pertaub, Chris Barker, and David M Clark. 2006. An Experimental Study on Fear of Public Speaking Using a Virtual Environment. CyberPsychology \& Behavior 9, 5: 627-633. https://doi.org/10.1089/cpb.2006.9.627

[152] S. H. Spence, C. Donovan, and M. Brechman-Toussaint. 2000. The treatment of childhood social phobia: The effectiveness of a social skills training-based, cognitive-behavioural intervention, with and without parental involvement. Journal of Child Psychology and Psychiatry and Allied Disciplines. https://doi.org/10.1017/S0021963099005934

[153] Susan H. Spence and Ronald M. Rapee. 2016. The etiology of social anxiety disorder: An evidence-based model. Behaviour Research and Therapy. https://doi.org/10.1016/j.brat.2016.06.007

[154] Dan J. Stein, Carmen C.W. Lim, Annelieke M. Roest, Peter de Jonge, Sergio Aguilar-Gaxiola, Ali Al-Hamzawi, Jordi Alonso, Corina Benjet, Evelyn J. Bromet, Ronny Bruffaerts, Giovanni de Girolamo, Silvia Florescu, Oye Gureje, Josep Maria Haro, Meredith G. Harris, Yanling He, Hristo Hinkov, Itsuko Horiguchi, Chiyi Hu, Aimee Karam, Elie G. Karam, Sing Lee, Jean Pierre Lepine, Fernando Navarro-Mateu, Beth Ellen Pennell, Marina Piazza, Jose Posada-Villa, Margreet ten Have, Yolanda Torres, Maria Carmen Viana, Bogdan Wojtyniak, Miguel Xavier, Ronald C. Kessler, Kate M. Scott, Mohammed Salih Al-Kaisy, Laura Helena Andrade, Guilherme Borges, Brendan Bunting, Jose Miguel Caldas de Almeida, Graca Cardoso, Alfredo H. Cia, Somnath Chatterji, Louisa Degenhardt, Koen Demyttenaere, John Fayyad, Chi yi Hu, Yueqin Huang, Norito Kawakami, Andrzej Kiejna, Viviane Kovess-Masfety, Daphna Levinson, John McGrath, Maria Elena Medina-Mora, Jacek Moskalewicz, Beth Ellen Pennell, Tim Slade, Juan Carlos Stagnaro, Nezar Taib, Harvey Whiteford, and David R. Williams. 2017. The cross-national epidemiology of social anxiety disorder: Data from the World Mental Health Survey Initiative. BMC Medicine 15, 1. https://doi.org/10.1186/s12916017-0889-2 
[155] Murray B. Stein, Martina Fuetsch, Nina Müller, Michael Höfler, Roselind Lieb, and Hans-Ulrich Wittchen. 2001. Social Anxiety Disorder and the Risk of Depression. Archives of General Psychiatry. https://doi.org/10.1001/archpsyc.58.3.251

[156] Lusia Stopa and David M. Clark. 1993. Cognitive processes in social phobia. Behaviour Research and Therapy. https://doi.org/10.1016/0005-7967(93)90024-O

[157] Robert J. Taormina and Jennifer H. Gao. 2013. Maslow and the motivation hierarchy: Measuring satisfaction of the needs. American Journal of Psychology. https://doi.org/10.5406/amerjpsyc.126.2.0155

[158] Unity Technologies. 2020. Unity Engine. Retrieved from https://unity.com/

[159] Sebastian Trautmann, Jürgen Rehm, and Hans-Ulrich Wittchen. 2016. The economic costs of mental disorders. EMBO reports. https://doi.org/10.15252/embr.201642951

[160] Robert J Ursano, Carl Bell, Spencer Eth, Matthew Friedman, Ann Norwood, Betty Pfefferbaum, J D Pynoos, Douglas F Zatzick, David M Benedek, and John S McIntyre. 2004. Practice guideline for the treatment of patients with acute stress disorder and posttraumatic stress disorder. Am J Psychiatry 161, 11 Suppl: 3-31.

[161] Stephanos Vassilopoulos. 2005. Social anxiety and the effects of engaging in mental imagery. Cognitive Therapy and Research. https://doi.org/10.1007/s10608-005-2993-4

[162] Sara Ventura, Rosa M. Baños, and Cristina Botella. 2018. Virtual and Augmented Reality: New Frontiers for Clinical Psychology. State of the Art Virtual Reality and Augmented Reality Knowhow. https://doi.org/10.5772/intechopen.74344

[163] Eric M. Vernberg, David A. Abwender, Keith K. Ewell, and Susan H. Beery. 1992. Social Anxiety and Peer Relationships in Early Adolescence: A Prospective Analysis. Journal of Clinical Child Psychology. https://doi.org/10.1207/s15374424jccp2102_11

[164] Margo C. Villarosa-Hurlocker, Adrian J. Bravo, Matthew R. Pearson, Mark A. Prince, Michael B. Madson, James M. Henson, Alison Looby, Vivian M. Gonzalez, Amber M. Henslee, Carrie Cuttler, Maria M. Wong, and Dennis E. McChargue. 2019. The Relationship Between Social Anxiety and Alcohol and Marijuana Use Outcomes Among Concurrent Users: A Motivational Model of Substance Use. Alcoholism: Clinical and Experimental Research. https://doi.org/10.1111/acer.13966

[165] Bruce E. Wampold, James W. Lichtenberg, and Charles A. Waehler. 2002. Principles of Empirically Supported Interventions in Counseling Psychology. The Counseling Psychologist 30, 2: 197-217. https://doi.org/10.1177/0011000002302001

[166] Melissa Watts. 2016. Avatar self-identification, self-esteem, and perceived social capital in the real world: A study of World of Warcraft players and their avatars.

[167] Justin W Weeks, Thomas L Rodebaugh, Richard G Heimberg, Peter J Norton, and Tejal A Jakatdar. 2009. "To avoid evaluation, withdraw": fears of evaluation and depressive cognitions lead to social anxiety and submissive withdrawal. Cognitive Therapy and Research 33, 4: 375-389.

[168] Adrian Wells and Costas Papageorgiou. 1998. Social phobia: Effects of external attention on anxiety, negative beliefs, and perspective taking. Behavior Therapy. https://doi.org/10.1016/S0005-7894(98)80037-3

[169] Taryn Williams, Coenraad J. Hattingh, Catherine M. Kariuki, Sean A. Tromp, Anton J. van Balkom, Jonathan C. Ipser, and Dan J. Stein. 2017. Pharmacotherapy for social anxiety disorder (SAnD). Cochrane Database of Systematic Reviews. https://doi.org/10.1002/14651858.CD001206.pub3

[170] Kate B. Wolitzky-Taylor, Jonathan D. Horowitz, Mark B. Powers, and Michael J. Telch. 2008. Psychological approaches in the treatment of specific phobias: A meta-analysis. Clinical Psychology Review. https://doi.org/10.1016/j.cpr.2008.02.007

[171] Susannah M. Wood and Antonia Szymanski. 2020. "The Me I Want You to See": The Use of Video Game Avatars to Explore Identity in Gifted Adolescents. Gifted Child Today. https://doi.org/10.1177/1076217519898217

[172] Maja Wrzesien, Juana Bretón-López, Cristina Botella, Jean Marie Burkhardt, Mariano Alcañiz, María Ángeles PérezAra, and Antonio Riera Del Amo. 2013. How technology influences the therapeutic process: Evaluation of the patienttherapist relationship in augmented reality exposure therapy and in vivo exposure therapy. Behavioural and Cognitive Psychotherapy. https://doi.org/10.1017/S1352465813000088

[173] Nick Yee and Jeremy Bailenson. 2007. The proteus effect: The effect of transformed self-representation on behavior. Human Communication Research. https://doi.org/10.1111/j.1468-2958.2007.00299.x

Received February 2021; revised June 2021; accepted July 2021. 